\title{
Why do East Asian children perform so well in PISA? An investigation of Western-born children of East Asian descent
}

\author{
John Jerrim \\ Institute of Education, University of London \\ November 2014 \\ http://johnjerrim.com/papers/
}

\begin{abstract}
A small group of high-performing East Asian economies dominate the top of the Programme for International Student Assessment (PISA) rankings. This has caught the attention of Western policymakers, who want to know why East Asian children obtain such high PISA scores, and what can be done to replicate their success. This paper investigates whether children of East Asian descent, who were born and raised in a Western country (Australia), also score highly on the PISA test. It then explores whether their superior performance (relative to children of Australian heritage) can be explained by reasons often given for East Asian students' extraordinary educational achievements. The results suggest that second-generation East Asian immigrants outperform their native Australian peers in mathematics by more than 100 PISA test points - the equivalent of two and a half years of schooling. Moreover, the magnitude of this achievement gap has increased substantially over the last ten years. Yet there is no 'silver bullet' that can explain why East Asian children excel academically. Rather a combination of factors, each making their own independent contribution, seem to be at play. Western policymakers should therefore appreciate that it may only be possible to catch the leading East Asian economies in the PISA rankings with widespread cultural change.
\end{abstract}

Key Words: PISA, East Asia, second-generation immigrants.

Contact Details: John Jerrim (J.Jerrim@ioe.ac.uk) Department of Quantitative Social Science, Institute of Education, University of London, 20 Bedford Way London, WC1H 0AL 


\section{Introduction}

The Programme for International Student Assessment (PISA) is a major cross-national study of school pupils' academic achievement. Since its launch in 2000, it has received an unprecedented amount of academic, media and public policy attention. Countries now eagerly await the tri-annual update from the Organisation for Economic Co-operation and Development (OECD) - the survey organisers - with particular interest in whether they have moved up or slid down the international rankings. Yet it now comes as little surprise when a small group of high-performing East Asian jurisdictions dominate the top spots, having consistently out-performed their Western competitors over the last decade and a half (and longer in other large-scale educational assessments such as the Trends in Mathematics and Science Study - TIMSS). Indeed, results from PISA 2012 suggest that the achievement gap between East and West remains as large as ever. This is particularly true in mathematics, where children in Shanghai, Singapore, South Korea and Hong Kong outscore their American, British and Australian counterparts by, on average, more than 40 test points (equivalent to more than one whole year of schooling).

Educational policymakers in the Western world have consequently begun to look East with an envious glare. Why are children in East Asia so much better at maths than us, and what can we do to catch up? Unfortunately, due to the sheer number of possible explanations, these are not straightforward questions to answer. Potential candidates include teacher selection and quality (OECD 2013), teaching methods (Leung 2006), work ethic (Kim 2005; Byun and Park 2012), 'tiger' parenting (Fu and Markus 2014), extensive out-of-school tuition (Bray and Kwok 2003), genetics / natural ability (Uttal 1997; Lynn and Meisenberg 2010), the value East Asian families place upon education (Francis and Archer 2005), the design of the school curriculum (Wu and Zhang 2006; Department for Education 2012), along with several others (including suggestions that this is due to foul play in the PISA tests - Time magazine 2013; The Economist 2014). Teasing out the combination of these factors driving East Asian educational success is not an easy task, with implications and policy recommendations for Western governments even less clear. Yet this has not stopped authoritative figures such as Andreas Schleicher (head of the OECD PISA programme) making strong suggestions about 'What Asian schools can teach the rest of the world' ${ }^{1}(\mathrm{CNN}$ 2013) highlighting the explanations that the OECD believe are key.

\footnotetext{
${ }^{1}$ http://edition.cnn.com/2013/12/03/opinion/education-rankings-commentary-schleicher/
} 
Difficulties in isolating why East Asian children excel academically perhaps reveal one of the main limitations of cross-national comparative assessments such as PISA. Although they are very effective 'benchmarking' tools, helping us to understand the magnitude of the achievement gap between different countries, they are limited in their ability to inform policymakers as to why this is the case (and what, therefore, should be done about it). Consequently, most attempts to explain East Asian success in PISA (including those ventured by the OECD) have relied heavily upon anecdotal evidence, where one simply tries to identify common patterns across such high-performing jurisdictions. Prominent examples include reports by Grattan Institute (2012) in Australia, the Department for Education (2012) in England, and Tucker (2011) in the United States. This is also common practice by the OECD, which at the release of PISA 2012 pointed towards anecdotal evidence that selection and training of teachers was a common feature amongst the top performing countries - implying that this was key to their success:

'Top performers, notably in Asia, place great emphasis on selecting and training teachers, encourage them to work together and prioritise investment in teacher quality, not classroom sizes' (OECD 2013)

Yet, in reality, evidence in support of such broad statements is often mixed, with few common patterns actually found across most high-performing jurisdictions (Micklewright et al 2014). Indeed, such an approach seems doomed to failure, given the limited number of 'observations' (countries) available, the large number of potential confounding factors, and the possibility of encountering the ecological fallacy (making spurious conclusions about individuals when examining correlations at the group level).

This paper is also concerned with the academic success of East Asian children in PISA - but takes a rather different approach. Specifically, it provides a case study of secondgeneration East Asian immigrants living in Australia. These children are born and raised in a Western country, and have thus been through its educational system (which scored around the OECD average in the PISA 2012 tests), curriculum and institutional structures. Yet their parents originated from a high-performing East Asian jurisdiction - bringing their culture and values with them. Thus a large part of the home and family environment experienced by these children will reflect their East Asian heritage (despite them being Australian nationals and

http://oecdinsights.org/2013/12/03/asias-students-storm-pisa2012/?utm source=rss\&utm medium=rss\&utm campaign=asias-students-storm-pisa-2012 
attending Australian schools). As East Asian educational success is often thought to be linked to cultural factors (e.g. the value placed upon education, willingness to invest in out-of-school tuition, instilling a hard-work ethic in their children, high aspirations) one might expect second-generation East Asian immigrants to outperform their native-Australian peers in the PISA maths test ${ }^{2}$. A key aim of this paper is to establish whether this is indeed the case, and the extent to which such differences in PISA maths performance can be explained by some reasons frequently given for East Asian students' high levels of academic achievement.

Australia provides the ideal setting in which to conduct this research. Culturally, it is very close to the West, sharing economic, political, historical and linguistic ties with Europe (particularly the United Kingdom) and North America. Moreover, like many Western countries, its recent PISA performance has been disappointing, with average maths test scores falling from 524 in 2003 to 504 in 2012 . Yet, geographically, Australia sits close to the East, with it being a prominent destination of East Asian migrants over a prolonged period of time. This, coupled with the large Australian PISA sample ${ }^{3}$, ensures a sufficient number of observations to make research into Western-born children of East Asian descent possible.

The results illustrate how Australian children with East Asian parents outperform their native Australian peers by an average of more than 100 PISA test points (equivalent to two and a half years of schooling). Moreover, while PISA test scores of native Australians declined substantially between 2003 and 2012, the scores of children with East Asian heritage improved rapidly. Yet there is little evidence that one single factor (a 'silver bullet') is able to explain the exceptionally high PISA test scores obtained by this group. Rather a series of factors combine, each making their own independent contribution. This includes selection of high quality schools, the high value placed upon education, willingness to invest in out-ofschool tuition, a hard work ethic and holding high aspirations for the future. Consequently, Western policymakers should not expect there to be an easy way to replicate East Asian students' extraordinary educational success. The reality is that this may only be possible over the very long-term, requiring a cultural shift where all families instil a strong belief in the

\footnotetext{
${ }^{2}$ We define a child as a 'native Australian' if they and both their parents are born in Australia.

${ }^{3}$ In most countries, a sample of 150 schools is selected to participate in PISA - with 35 pupils randomly selected from within each. In PISA 2012, the Australian sample was increased to 775 schools to allow comparisons between the various Australian states.
} 
value of education amongst their children (along with the realisation that hard work and sacrifice may be needed to achieve it).

The paper now proceeds as follows. Section 2 describes the Australian PISA 2012 data, with section 3 outlining the empirical methodology. Section 4 compares PISA maths test scores of Australian natives to those of second-generation East Asian immigrants. This includes a detailed investigation of whether any differences found can be explained by reasons commonly given for East Asian children's exceptionally high levels of academic achievement. Discussion and conclusions follow in section 5.

\section{Data}

The Programme for International Student Assessment (PISA) is a cross-national study of 15yearold children's academic achievement. Since 2000, it has been conducted every three years by the OECD, with the 2012 round including approximately half a million children from 65 economies. This paper focuses upon the Australian data collected as part of PISA 2012 (downloadable from http://www.acer.edu.au/ozpisa/the-australian-pisa-data-files). A total of 828 Australian schools were selected, with probability proportional to size, to participate in the study. Within each of these sampled schools, 20 pupils were randomly selected to sit the PISA test ${ }^{4}$. School and pupil response rates were 98 percent and 87 percent respectively. The final Australian sample comprised 14,481 pupils from 775 schools, including 276 second-generation East Asian immigrants. Survey and Balanced Repeated Replication (BRR) weights are provided by the survey organisers to adjust for the complex survey design (e.g. stratification and the clustering of pupils within schools) and to correct estimates for the small amount of non-random non-response.

The PISA test covers three academic domains (mathematics, reading and science) and took two hours to complete. All questions and test procedures have been designed with crossnational comparability in mind, with the survey organisers having strict protocols for translation, sampling, response rates and testing procedures. The focus of PISA 2012 was children's maths skills, and is the domain of interest in this paper. Five 'plausible values' have been produced by the survey organisers using a Rasch model, each representing a

\footnotetext{
${ }^{4}$ This represented a change from previous PISA cycles in Australia, where 48 pupils were randomly selected within each school. All age-eligible Indigenous students were also included in the sample to ensure a sufficient number of observations to allow analysis by this sub-group.
} 
different estimate of children's 'true' proficiency in mathematics. These plausible values all have a mean of approximately 500 and a standard deviation of approximately 100 across OECD countries, with 40 PISA points being roughly equal to an additional year of schooling (OECD 2010: 110). Recommended practice is followed when analysing these data (OECD 2009), with five separate estimates of the statistic of interest produced (once using each of the plausible values) and then an average of these estimates taken. To aid interpretation of results, regression model estimates will be presented in terms of international standard deviations.

As part of PISA, children complete a background questionnaire. This included a question about the country of birth of the child, their mother and their father. Tick-box options were provided for the major countries of birth within the Australian population (e.g. Australia, New Zealand, England, China, the Philippines) with an open text field available for those who indicated the 'other' category. At least 96 percent of respondents provided valid answers to each of these questions, with specific country of birth provided in the Australian national dataset $^{5}$.

A child is defined as an Australian native if they and both their parents were born in Australia $^{6}$. In contrast, a child is defined as a second-generation immigrant from a highperforming East Asian country if they were born in Australia, and at least one of their parents were born in the following countries ${ }^{7}$ :

- Hong Kong

- Japan

- Singapore

- China

\footnotetext{
${ }^{5}$ Such information is not available in the international database provided on the OECD website. It is also not available for most of the countries that participate in the PISA study (at least at such a fine level of detail).

${ }^{6}$ Indigenous children (who form approximately three percent of the Australian population) have been excluded from the analysis. My experimentations suggest that this sample restriction has little impact upon the substantive conclusions reached.

${ }^{7}$ Of the children defined as a second-generation immigrant from a high-performing East Asian jurisdiction, 68 percent reported both of their parents being born in one of the countries listed. Nineteen percent reported just their mother being born in a high-performing country, and 10 percent just their father. Around 80 percent of the high-performing second-generation East Asian group have at least one parent born in China.
} 
- Republic of Korea (South Korea)

- Taiwan

These origin countries have been chosen as they represent the group of high-performing East Asian nations consistently found at the top of the PISA and TIMSS maths rankings ${ }^{8}$. Note that children in both groups were born in Australia and were attending an Australian school at age 15. It therefore does not seem unreasonable to assume that the majority have been educated within the Australian schooling system.

The primary concern is differences in PISA maths scores between these two groups. However, it is important to recognise that migrants are self-selecting (Borjas 1988) and thus on average 'more able, ambitious, aggressive, entrepreneurial or otherwise more favourably selected than similar individuals who chose to remain in their place of origin' (Chiswick 1999:181). Significantly, the same characteristics are also likely to be associated with their offsprings' academic achievement ${ }^{9}$. One may therefore question: are the high test scores of second-generation East Asian immigrants simply reflecting the selective nature of this group?

This possibility is explored in two ways. First, the analysis considers whether large differences in PISA scores persist after controlling for differences in observable characteristics (e.g. gender, parental education, social class, wealth, geographic location). This will thus account for the fact that second-generation East Asian children typically have more educated parents, are more likely to be male and more likely to live in Victoria than the native Australian group (see Table 1). Of course, there are a host of other potentially important characteristics of immigrant families (e.g. drive, determination, aspiration) which are unobserved and cannot be controlled. Second-generation East Asian immigrants and other migrant groups are therefore also compared. The intuition is that immigrants from other regions/countries will have been through a similar migration decision-making process and

\footnotetext{
${ }^{8}$ One might argue that Vietnam could also be included in this group, given this country's relatively strong performance in PISA 2012. However, the decision was made to exclude this country from the 'high-performing' group as, although its PISA maths score (511) was above that of many Western countries (including the United Kingdom, Australia and the United States) it remained significantly below the leading East Asian nations such as Singapore (573), Hong Kong (561), South Korea (554) and Japan (536).

${ }^{9}$ In other words, more able and ambitious individuals are not only more likely to migrate, but are also more likely to ensure their children works hard and achieves highly in school.
} 
met the same entry requirements (in terms of the skills needed to enter the country) as immigrants from high-performing East Asian countries. Consequently, they are also likely to be similar in terms of unobservable factors driving migrant self-selection (e.g. drive, ambition, motivation). Thus, if PISA scores of second-generation East Asian immigrants are also high relative to second-generation immigrants from other countries, it becomes increasingly unlikely that their exceptional educational performance can be solely attributable to the self-selected nature of this group.

Second-generation immigrants from three other regions/countries are therefore also considered. The first is formed of children whose parents were born in another (not highperforming) East Asian country:

- Malaysia

- Philippines

- Indonesia

- Thailand

- Cambodia

- Vietnam

- Laos

- Democratic People's Republic of Korea (North Korea).

Second-generation immigrants from these countries form a particularly interesting comparison group due to their similar ethnic and cultural origins. Second-generation immigrants where at least one parent was born in India or surrounding countries are also considered, due to similar stereotypes often made regarding the value they (like East Asian families) place upon their children's education:

- India

- Pakistan

- Nepal

- Bangladesh

Finally, second-generation immigrants from the United Kingdom are also considered. This country has historically been the single biggest source of immigration into Australia (Australian Bureau of Statistics 2013), and has a Western culture and heritage very similar to the 'native' (two Australian parents) group. 
Children were asked a range of questions about their attitudes towards mathematics, out-of-school activities, work ethic, parental attitudes and aspirations for the future as part of the PISA background questionnaire. However, this part of the survey used a 'rotated-design', where randomly selected sub-samples of children were asked different sets of questions. Specifically, each child randomly received one of three possible questionnaire booklets. These included a core component (common to all booklets) and a rotated component (which differed between booklets). The intuition is that this allows a greater breadth of content to be covered in the background questionnaire, though at the loss of some statistical power. The main implication is that certain attitudinal items and scales are Missing Completely At Random (MCAR) for some children by design ${ }^{10}$. Throughout the analysis Multiple Imputation by Chained Equations (MICE) is used to take this aspect of the PISA questionnaire design into account. This ensures that parameter estimates remain unbiased while maximising statistical power (uncertainty due to missing data is also incorporated into the estimation of standard errors). To test the robustness of results, a complete case analysis (where only observations with all available data are included in the final sample) and a "missing dummies" analysis (using dummy variables to maintain the full sample but without imputing any information) is also performed. All substantive findings remain largely unchanged, with further details provided in Appendix A.

The rotated part of the PISA questionnaire included the following question on the amount of time children study outside of school:

'Thinking about all school subjects: on average, how many hours do you spend each week on the following?' \{When answering, include time spent on the weekend too

With information gathered for six activities (homework set by teachers, 'guided' homework, personal tuition, classes with a commercial company, study with a family member and repeating content from school lessons on a computer). This was accompanied by a series of questions designed to capture children's work ethic, perseverance, self-efficacy, aspirations, interest, motivation and subjective norms regarding mathematics (among other things). These typically took the form:

\footnotetext{
${ }^{10}$ This is one of the few occasions where MCAR is an appropriate assumption; one can have confidence that data are missing completely at random due to the random assignment of questionnaire booklets to children (i.e. the missing data mechanism is, by design, random).
} 
'I study hard for mathematics quizzes'

- Strongly agree

- Agree

- Disagree

- Strongly disagree

With the above being an example from the battery of questions designed to elicit children's work ethic. (Appendix B provides full details on the questions asked as part of each scale). Children's responses were converted by the survey organisers into scales using a one-parameter (Rasch) model. To facilitate interpretation of results, each scale has been re-standardised to have a mean of 0 and standard deviation of 1 within the Australian population. Ensuring the cross-cultural validity of such scales is a key feature of PISA, with a thorough and closely monitored translation process and a range of psychometric techniques applied to test for construct validity. Further details can be found in the PISA 2012 technical report (see OECD 2014).

Finally, children were also asked two questions attempting to capture the effort they put into completing the PISA test. Butler and Adams (2007) describe this 'effort thermometer' in detail, with their illustration of the questions asked presented in Figure 1. The intuition is that, as children and their schools have little riding on the outcome (i.e. PISA is a 'low-stakes' assessment), they may not exert maximum effort on the test. The effort thermometer has been designed to elicit such information from participants. This can then be used to control for differences in reported test effort between different groups (Australian natives and secondgeneration immigrants in this application).

\section{$<$ Figure $1>>$}

Table 1a provides information on the distribution of selected demographic characteristics for the native and second-generation immigrant samples. There are slightly more East Asian boys than girls (56 percent) compared to Australian natives (51 percent). East Asian parents also tend to hold higher levels of education - half of East Asian fathers hold a university degree compared to just a quarter of Australian natives ${ }^{11}$. Yet there is no evidence that East Asian parents work in more prestigious occupations (the average of the

\footnotetext{
${ }^{11}$ In Table 1, ISCED level 5A+ is equivalent to a bachelor's degree or higher. See notes to Table 1 for further information.
} 
International Socio-Economic Index - ISEI - is around 50 for all groups ${ }^{12}$ ) and actually have lower levels of the PISA measure of household wealth (their index of wealth is 0.22 standard deviations below the Australian mean ${ }^{13}$ ). Interestingly, children of East Asian heritage mostly live in Victoria (57 percent) or New South Wales (23 percent), and continue to speak a language other than English in the family home (52 percent $)^{14}$.

\section{$<$ Table 1 >}

Average values on the (standardised) PISA scales can be found in Table $1 \mathrm{~b}$ (Appendix B provides the questions asked as part of each scale and the distribution of responses to one particular item). These generally conform to many of the stereotypes often made about children from East Asian backgrounds. For instance, they report spending substantially more time studying outside of school hours (15 hours versus 9 hours for Australian natives), and score very highly on the work ethic (0.33 standard deviations above the Australian mean), subjective norms (0.43) and maths behaviour (0.67) scales. They also hold very high aspirations; 94 percent expect to enter university compared to just 58 percent of the native Australian group. There is also a suggestion that East Asian children have higher levels of instrumental motivation, are more likely to believe they can succeed if they work hard enough (i.e. perceived control) and less likely to blame others for failure, than their native Australian peers. Overall, these scales follow expected patterns, with each potentially explaining why Australian children of East Asian descent score so highly on the PISA maths test.

\footnotetext{
${ }^{12}$ The ISEI index is a continuous measure of occupational prestige (see Ganzeboom and Treiman 1996). It has been designed to increase comparability of occupational status across countries, with higher values indicating more prestigious jobs.

${ }^{13}$ Children are asked questions about household possessions (e.g. number of computers, number of cars, whether they have a dishwasher). The survey organisers use this information to create a measure of wealth. ${ }^{14}$ There is very little difference in average PISA maths test scores between second-generation East Asian immigrants who speak English in the family home and those who do not ( 3 PISA points or 0.03 standard deviations).
} 


\section{Methods}

A series of Ordinary Least Squares (OLS) regression models are estimated. These take the form:

$$
Y_{i j}=\alpha+\beta \cdot I_{i}+\delta \cdot D_{i}+\gamma \cdot C_{i}+\mu_{j}+\varepsilon_{i j}
$$

Where:

$\mathrm{Y}=$ Children's PISA maths test scores

$\mathrm{I}=\mathrm{A}$ vector of second-generation immigrant dummy variables (reference $=$ Australiannatives)

$\mathrm{D}=\mathrm{A}$ vector of demographic characteristics (mother's and father's education, mother's and father's occupation, household possessions/wealth, language spoken at home, state, urban / rural location, family structure, gender, indigenous status and pupil age).

$\mathrm{C}=\mathrm{A}$ series of control variables capturing common explanations for East Asian pupils' educational success (outlined below)

$\mu=$ School-level fixed effects

$\varepsilon=$ Individual random error term

$\mathrm{i}=$ Pupil i

$\mathrm{j}=$ School $\mathrm{j}$

The following section begins by presenting unconditional differences in PISA maths test scores between Australian natives and the various second-generation immigrant groups. In other words, the model presented in (1) is estimated with $\delta, \gamma$ and $\mu$ constrained to 0 , and $\beta$ the sole parameter of interest.

A series of control variables are then sequentially added to the model, the primary interest being in how estimates of $\beta$ change across specifications. First, a vector of demographic characteristics is included (i.e. $\delta$ is now estimated rather than being constrained to 0 ). This includes pupil age and gender, maternal and paternal education, occupation and work status, state of residence, language most often spoken at home and a proxy for household wealth. Hence $\beta$ will now capture differences between natives and second- 
generation immigrants, having accounted for any possible differences in these basic demographic characteristics.

A school-level fixed effect is then added in specification 3 (i.e. $\mu_{j}$ is now also estimated $)^{15}$. This removes all remaining between-school variation, with $\beta$ now capturing differences between Australian natives and second-generation immigrants conditional upon them attending the same school (as well as having the same demographic characteristics). It is important to realise that the change in $\beta$ between the second and third specification will not necessarily capture the 'effect' of schools (and their contribution to the native-East Asian achievement gap) per se. Rather it captures a mix of school effects, selection effects (e.g. East Asian parents choosing higher quality schools for their children) and other previously unmeasured factors that vary between children attending different schools (e.g. neighbourhood and peer effects).

From specification 4 onwards, the extent to which a series of factors can explain within school differences between Australian-natives and second-generation East Asian children is examined (i.e. reasons why children of East Asian descent outperform children of Australian heritage, even when they have the same demographic characteristics and attend the same school). The first of these factors is test effort - are the superior PISA scores of East Asian children simply a reflection of their determination to perform well on the low-stakes PISA test? Time spent studying outside of school is then added to the model. This captures the widely held view that the extra time and money East Asian families invest in out-ofschool tuition is a key reason for their children's exceptional educational performance. Alternatively, it is often claimed that East Asian children's high test scores can partly be attributed to their work ethic, and a cultural belief that anyone can succeed if they try hard enough - i.e. that the Western attitude of not being 'naturally' good at something (e.g. maths) is no excuse for failure (Uttal 1997). This possibility is accounted for by controlling the PISA 'work ethic', 'perceived control', 'attributions to failure' and 'perseverance' scales ${ }^{16}$. A

\footnotetext{
${ }^{15}$ It is not possible to apply the BRR replicate weights within Stata when a school fixed effect is included in the model. The clustering of pupils within schools is therefore taken into account via the application of cluster-robust standard errors.

${ }^{16}$ These scales were created from children's responses to statements such as: 'If I put in enough effort I can succeed in mathematics', 'I do badly in mathematics whether or not I study for my exams' and 'Sometimes I am just unlucky'.
} 
similar intuition holds in subsequent models, where additional variables are added capturing views that East Asian students' strong PISA performance is due to their high aspirations, parental attitudes towards the importance of education (particularly mathematics), children's attitudes towards school and their instrumental motivation (that doing well in school is important for getting a good job). The following section will discuss whether adding these factors to the model helps to explain differences in maths achievement between children of Australian versus East Asian descent.

It is important to note that the modelling process outlined above will not necessarily reveal the causal effect of any given factor. Some variables may be more reliably recorded than others (e.g. the PISA effort thermometer is based upon a single item, whereas other variables are a composite scale), while in some of the later models even the direction of causation may be unclear (e.g. do East Asian pupils have high test scores because of their high aspirations, or are their high aspirations driven by their high test scores)? What the estimates do provide, however, is a detailed decomposition of the native-East Asian test score gap - examining the extent to which the high PISA test scores of the latter can indeed be 'explained' (in a statistical sense) by many of the common explanations given for their success.

\section{Results}

Figure 2 presents average PISA maths test scores for the native-Australian and secondgeneration immigrant groups (white bars). Analogous figures are also provided for a selection of comparator countries (grey bars). The strong performance of Australian children of East Asian heritage is striking. Their score of 605 is significantly above that of any other group, outperforming children with two Australian parents by more than 100 test points (i.e. one whole standard deviation). Thus, despite being born and raised in a Western country with an 'average' performing education system, Australian children of East Asian descent obtain test scores consistent with countries at the top of the PISA rankings. This provides further motivation for a detailed investigation of this group; they demonstrate high levels of academic proficiency that educational policymakers would like all young people to achieve.

\section{$<$ Figure $2>>$}


Table 2 presents results from the first three regression model specifications. All figures refer to differences relative to the native Australian group, and are presented in terms of international standard deviations ${ }^{17}$. Model 1 presents the unconditional estimates. Consistent with Figure 2, second-generation immigrants from high-performing East Asian countries achieve much higher scores than all other groups. Moreover, parameter estimates for secondgeneration immigrants from other countries are of a reasonable magnitude and significantly greater than zero at the five percent level. In other words, second-generation immigrants from India, the United Kingdom and other (not high-performing) East Asian countries also achieve higher scores (on average) than Australian natives on the PISA test.

\section{$<<$ Table 2 >}

Model 2 adds controls for a range of demographic characteristics (e.g. age, gender, parental education) as detailed in section 3. This leads to a non-trivial decline in the highperforming East Asian parameter estimate, falling from 1.02 to 0.84 standard deviations (102 to 84 PISA points). Nevertheless, differences between children of East Asian heritage and their native-Australian peers remain large (equivalent to more than two years of schooling) and statistically significant at the five percent level. Thus, although positive selection among migrant families seems to partly explain the achievement gap, it is by no means the only factor at play. In contrast, the second-generation Indian and second-generation UK parameter estimates are no longer statistically significant at conventional thresholds. Thus, unlike children of East Asian heritage, the comparatively high test scores achieved by these groups can largely be explained by differences in observed background characteristics alone.

School fixed effects are included in model 3. Consequently, any remaining between school variation has now been removed. This causes the high-performing East Asian parameter estimate to fall by more than half, from 0.84 standard deviations (84 PISA points) to 0.41 (41 PISA points). This possibly indicates that East Asian families choose to send their children to (or live in neighbourhoods with) 'better' schools than Australian parents, which in turn leads to a substantial difference in their academic achievement. Indicative evidence on this issue is presented in Appendix C, which illustrates how children of East Asian descent generally attend higher quality schools than their native Australian peers (even after conditioning upon a range of family background characteristics). This finding does, however, require careful interpretation. On the one hand, it may represent a selection effect. For

${ }^{17}$ Multiplying figures in the results table by 100 gives differences in terms of PISA points. 
instance, East Asian parents may be choosing to send their children to what they believe are the 'best' schools, due to the importance they attach to education. The school fixed effect may thus be partly picking up this important aspect of East Asian culture. Alternatively, the school fixed effect may be capturing other residual background influences not fully controlled in model specification 2 (e.g. local neighbourhood effects). This includes the possibility that, as school assignment is often based upon location of the family home, residential choice (rather than school choice) are being picked up by the school fixed effect instead $^{18}$. Similarly, one cannot interpret the striking decline in parameter estimates between model 2 and 3 as representing the 'causal' influence of schools, as the school fixed effect will also incorporate things like peer effects. What these results do show, however, is that a combination of factors occurring at the school level (e.g. school selection, school effectiveness, peer effects) form a key part of the explanation as to why children of East Asian heritage outperform children with an Australian background.

Yet, even once all between school variation has been removed, the gap in achievement between children of Australian and East Asian heritage remains large, standing at approximately 40 PISA points (equivalent to one whole year of schooling). Moreover, parameter estimates for all other second-generation immigrant groups are now small and statistically insignificant at the five percent level. This suggests that East Asian parents are doing additional things to boost their children's achievement, relative to both Australian natives and other immigrant families from a similar background, whose children attend the same school. In other words, out-of-school factors (e.g. culture and home environment) also seem to be playing a vital role.

Before adding further explanatory variables to the model, the issue of trends over time is briefly considered. Australia has suffered a steep decline in the PISA rankings over the last decade, with recent research suggesting that this was driven by falling performance amongst private school pupils and the highest achievers (Ryan 2013). But has the performance of Australian children with East Asian heritage followed this pattern? Or have their test scores increased, and thus their lead over Australian natives grown? This question is answered by re-estimating models 1, 2 and 3 in each of the PISA 2003, 2006 and 2009 datasets. Findings

\footnotetext{
${ }^{18}$ The Department of Education and Early Child Development in Victoria (the state where more than half the sample of second-generation East Asian immigrants live - see Table 1A) notes that children usually attend their nearest secondary school. However, families have the choice to send their child to another secondary school (or a catholic or independent school) if it has places available. See http://www.education.vic.gov.au/school/parents/secondary/Pages/choosing.aspx for further details.
} 
are summarised in Figure 3. This plots the difference in standardised PISA test scores between Australian natives and second-generation East Asian immigrants, based upon estimates from model 2 (black line), model 3 (dashed grey line starred markers) and the difference between the two (dashed grey line triangular markers).

\section{$<$ Figure $3>>$}

There is strong evidence that second-generation East Asian immigrants have managed to increase their lead over the native-Australian group. While PISA maths test scores of the latter have declined steadily from 528 in 2003 to 518 in 2006, 511 in 2009 and 499 in 2012, those of second-generation East Asian immigrants have risen from 565 in 2003, to 582 in 2006, 579 in 2009 and 605 in 2012. The solid black line in Figure 3 consequently illustrates the substantial increase in the maths achievement gap between these groups over this period. This linear trend is statistically significant at the five percent level, highlighting how PISA scores of Australian children with East Asian heritage have improved, even though performance of the country as a whole has been in stark decline. Moreover, the grey lines plotted in Figure 3 suggest that this cannot simply be attributed to East Asian families becoming increasingly selective in their choice of school. Indeed, within school differences between natives and second-generation East Asian immigrants have increased from 0.17 to 0.40 standard deviations between 2003 and 2012 (this linear trend is also statistically significant at the five percent level). Consequently, there is strong evidence that East Asian families have extended their children's already large academic lead over recent years.

Table 3 attempts to explain the remaining within school differences between children of Australian and East Asian heritage observed in PISA 2012. First, effort on the PISA test is controlled, resulting in trivial declines in the second-generation immigrant parameter estimates ( $\beta$ falls from 0.407 to 0.406 for the high-performing East Asian heritage group). This reflects both the weak correlation between test effort and PISA scores (Pearson correlation coefficient $=0.05$ ) and that reported test effort differs little between native and second-generation immigrants (recall Table 1b). There is thus little evidence that the exceptional performance of East Asian children on PISA is simply due to the greater effort they put into this 'low stakes' test.

$<$ Table $3>>$ 
Specification 5 adds to the model time spent studying outside of school. This includes both the total amount of time, and the activities on which this time is spent (e.g. homework, private tuition etc). The second-generation East Asian parameter estimate declines by approximately 25 percent - from 0.406 standard deviations (41 PISA points) to 0.290 (29 PISA points). This is consistent with the view that out-of-school tuition (or what it proxies e.g. family commitment to their children's education) makes an important contribution to East Asian children's success in PISA. One important implication is that this illustrates how PISA test scores are not measuring the 'quality' of a country's schooling system per se. Rather, PISA test scores are influenced by several factors, many of which are beyond schools' control (e.g. the willingness of parents to provide their children with extra tuition). However, it is equally important to note that large differences in PISA maths test scores remain between Australian natives and second-generation East Asian immigrants, even after this factor has been taken into account.

Four of the PISA scales are included in model 6: work ethic, perceived control, attributions to failure and perseverance. Together, these attempt to capture the view that East Asian children's high test scores can be attributed to their hard work ethic, belief that anyone can succeed if they put in enough effort, and that they do not give up easily when met with a challenge. This results in another appreciable drop of 0.05 standard deviations (5 PISA points) in the second-generation high-performing East Asian parameter estimate, from 0.290 (29 PISA points) to 0.244 (24 PISA points). Given the array of factors already taken into account, this represents a reasonably sizeable decline. It thus suggests that East Asian parents' ability to instil a hard work ethic in their offspring, and a belief that they can succeed if they try hard enough, does indeed make an important contribution to their high PISA test scores.

Model 7 adds the subjective norms scale. This includes children's responses to statements like 'my parents believe it's important for me to study mathematics', thus partly capturing the influence of parental views on the importance of education (and mathematics in particular). Interestingly, this adds little explanatory power, with the high-performing East Asian parameter estimate hardly changing (it actually increases slightly from 0.244 to 0.247 ). This suggests that the influence of such factors is likely to have already been proxied by other variables included in the model. For instance, parents who believe it is important to study maths are also more likely to pay for out-of-school maths tuition, with the effect of the former having already been captured once the latter had been controlled in specification 5 . 
A similar story emerges from model 8 , where the instrumental motivation and attitude towards school scales are included. These reflect children's answers to questions like 'learning mathematics is worthwhile for me because it will improve my career prospects' and 'trying hard at school will help me get a good job.' Their inclusion leads to a small increase in the East Asian parameter estimate, from 0.247 to 0.259 . Hence, students' views on the use of maths in their future careers do not explain any of the remaining difference in maths achievement between children of Australian and East Asian descent (over and above the other variables already included in the model).

Finally, models 9 and 10 control for children's mathematics behaviour (e.g. whether they take part in maths competitions) and their educational expectations. Including the former reduces the high-performing East Asian parameter estimate down to 0.202 standard deviations (from 0.259 in model 8), while adding the latter reduces this further to 0.148 . This is substantial, given the wide array of factors already controlled, potentially indicating that doing more maths related activities and holding high educational aspirations play an important role in driving East Asian children's educational success. Some caution is required when interpreting these results, however, due to the potentially endogenous nature of these variables (e.g. rather than high aspirations leading to high achievement, the direction of causality may be the other way around).

Thus, by the end of the modelling process, approximately 85 percent of the difference in maths achievement between Australian natives and second-generation immigrants from a high-performing East Asian country has been explained (in a statistical sense) ${ }^{19}$. No single factor has stood out as the cause of the difference in achievement between these groups. Rather a combination of socio-economic characteristics, school selection, values placed upon education, out-of-school tuition, work ethic, attitudes towards what drives success and high aspirations for the future, seem to be at play. Yet, even after accounting for such a wide set of characteristics, there remains a statistically significant difference of 15 PISA points $(0.148$ standard deviations) between children of Australian and East Asian heritage. There are thus important factors not observed within the PISA dataset, and not adequately proxied by other variables, that are partly responsible for the exceptionally high test scores obtained by second-generation East Asian immigrants. Potential candidates include educational

\footnotetext{
${ }^{19}$ This is based upon the high-performing East Asia parameter estimate falling from 1.022 in model 1 to 0.148 in model 10 .
} 
experiences earlier in life (e.g. quality of primary or pre-school school care - see Jerrim and Choi 2014), gaining access to higher quality teachers within schools ${ }^{20}$ or inherent ability ${ }^{21}$. Unfortunately, examining the influence of such factors is beyond the scope of this paper and, indeed, the data currently available. Consequently, investigating the influence of such factors remains an important area for future research.

\section{Conclusions}

The high PISA test scores of East Asian children have become the envy of educational policymakers across the Western world. Previous attempts to explain their phenomenal performance have either drawn upon anecdotal evidence (Grattan Institute 2012; OECD 2013) or by simply examining a set of bivariate cross-national correlations (Leung 2006). In contrast, this paper has examined PISA maths test scores of children with East Asian parents who were born and raised in a Western country (Australia). The analysis suggests that this group score, on average, more than 600 points on the PISA test, putting them second to only Shanghai-China in the PISA rankings. They thus replicate the high PISA test scores of children living in the high-performing East Asian economies, despite being educated within an 'average' Western educational system. These findings are consistent with the findings of Feniger and Lefstein (2014), who argue that that maths skills of Chinese children living in Australia and New Zealand are more similar to those of children in Shanghai than their native Australian and New Zealand peers. Yet there is little evidence that a single factor can explain the exceptionally strong PISA performance of this group. Rather a combination of school selection, a high value placed upon education, substantial out-of-school tuition, hard work ethics, a belief that anyone can succeed with effort and high aspirations for the future, all play an important, inter-linked role.

These findings have important implications for Western policymakers attempting to catch the high-performing East Asian countries at the top of the PISA rankings. First, the experience of second-generation East Asian immigrants in Australia illustrates how high-

\footnotetext{
${ }^{20}$ The PISA 2012 dataset does not include a measure of teacher quality per se. It does, however, include a scale recording pupils' views on their maths teachers (and their teaching practices). My experimentations suggest, however, that this is unable to explain much additional variation in maths achievement over and above the factors already included in the model.

${ }^{21}$ This is clearly a controversial issue. The point is raised here to recognise that there has been some debate about this matter within the literature (see Uttal 1997 and Lynn and Meisenberg 2010) and that the empirical evidence presented is unable to conclusively support or reject such claims.
} 
level maths skills can be developed even within average-performing educational systems (including by children of average and low socio-economic backgrounds). Second, the attitudes and beliefs East Asian parents instil in their children make an important contribution to their high levels of academic achievement. Yet as such factors are heavily influenced by culture and home environment, they are likely to be beyond the control of schools. Greater recognition needs to be given to this point in public discourse. Indeed, policymakers should make it clear that there are many influences upon a country's PISA performance, and that climbing significantly up these rankings is unlikely to be achieved by the efforts of schools alone. (See Strand 2010 and Strand 2014 for a discussion of the limits of school effectiveness). Finally, high-ranking PISA countries may well provide Western policymakers with valuable insights into how their own education systems might be improved. But any subsequent policy action must be supported by a wider evidence base - policymakers should not rely upon PISA alone. For instance, one does not want to erroneously conclude that rote learning helps to improve children's maths skills, simply because this technique is often practised within East Asian schools. Indeed, the fact that children of East Asian heritage perform just as highly in the Australian education system (whose schools and teachers do not routinely use such techniques) would actually seem to contradict such views. This highlights the care that needs to be taken before policy is borrowed from other countries; due consideration of the wider literature (and sources of evidence other than PISA) is always needed.

It is equally important to reflect upon the limitations of this study and to stress the need for further work. First, the ability to draw causal inferences is limited, partly due to the cross-sectional nature of the PISA dataset (providing a snapshot of children's skills at one particular point in time). Further evidence on the dynamics of East Asian children's educational achievement is required, including how their skills develop as they move through primary and secondary school. Developing such a longitudinal component to the PISA study would of course be a challenge, but is nevertheless critical to enhancing our understanding of the mechanisms behind East Asian pupils' extraordinary educational success. Second, it is important to remember that immigrants are a self-selecting group, who tend to be more ambitious and driven than individuals who remain in their country of birth (Borjas 1988; Chiswick 1999). Migrant selectivity, rather than East Asian culture, may therefore be driving second-generation East Asian immigrants high test scores. Although a comparison of test scores across immigrant groups has been conducted to shed some light on this issue, one still 
cannot rule out the possibility that migrant selectivity is having some kind of influence upon results. Third, the sample of second-generation immigrants analysed is reasonably small in size, while mathematics has been the only subject considered. It could be that mathematics has particularly high cultural value amongst East Asian groups, meaning the extent it is possible to generalise from these results to other subject areas is limited. Finally, this paper has focused upon the experiences of East Asian children living in one particular Western country. Future work should try to establish whether findings generalise to East Asian children born and raised in other parts of the Western world. Unfortunately, due to data restrictions and small sample sizes, this is not currently possible for other countries (e.g. the Canada, Europe and the United States) - at least in terms of PISA test scores ${ }^{22}$. Yet such work should be pursued as soon as possible, as it may provide even stronger evidence that East Asian children's success in PISA does not depend upon the schooling system (and other institutional structures) to which they are exposed.

In the meantime, this paper has the potential to make an important contribution to contemporary educational policy debate. It has illustrated how Australian children of East Asian heritage perform just as highly on the PISA maths test as children within the highperforming East Asian jurisdictions. This brings into question whether it really is the schooling system (and associated teaching methods) in these countries that are responsible for their dominance of the PISA and TIMSS rankings. Indeed, results suggest that making changes to the schooling system and teaching practices alone may be insufficient for Western countries to catch the top-performing East Asian nations. Rather, this goal may only be achieved with widespread cultural change, where a hard work ethic and a strong belief in the value of education is displayed by all families and instilled in every child.

\footnotetext{
${ }^{22}$ In England, it is possible to investigate the maths achievement of second-generation Chinese pupils in high stakes national exams. Strand (2010) demonstrates the exceptional attainment of Chinese students at age 11, along with the remarkable progress they make from age 7. Moreover, he shows this holds for both boys and girls, and pupils from low income households (as measured by eligibility for Free School Meals). This suggests that exceptional performance of second-generation East Asian immigrants in mathematics exams may generalise to England as well.
} 


\section{References}

Australian Bureau of Statistics. 2013. 'Migration, Australia, 2011-12 and 2012-13'. Accessed 01/08/2014 from http://www.abs.gov.au/AUSSTATS/abs@.nsf/DetailsPage/3412.0201112\%20and\%202012-13? OpenDocument.

Borjas, George. 1988. 'Immigration and self-selection'. NBER working papers number 2566. Accessed 08/09/2014 from http://www.nber.org/papers/w2566.

Bray, Mark and Percy Kwok. 2003. 'Demand for private supplementary tutoring: conceptual considerations, and socio-economic patterns in Hong Kong'. Economics of Education Review 22(6):611-20.

Butler, Jayne and Raymond Adams. 2007. 'The impact of differential investment of student effort on the outcomes of international studies'. Journal of Applied Measurement 8(3): 279304.

Byun, Soo-yong and Hyunjoon Park. 2012. 'The academic success of East Asian American youth: The role of shadow education'. Sociology of Education 85(1): 40-60.

Chiswick, Barry. 1999. 'Are immigrants favourably self-selected?' American Economic Association papers and proceedings: 181-85. Accessed 08/09/2014 from http://web.stanford.edu/group/scspi/_media/pdf/Reference\%20Media/Chiswick_1999_Immig ration.pdf.

CNN. 2013. 'Opinion: What Asian schools can teach the rest of the world'. Accessed 05/09/2014 from http://edition.cnn.com/2013/12/03/opinion/education-rankings-commentaryschleicher/

Department for Education. 2012. 'What can we learn from the English, mathematics and science curricula of high- performing jurisdictions?' Department for Education Research Report DFE-RR178. London (England): Department for Education. Accessed 22/07/2014 from www.gov.uk/government/uploads/system/uploads/attachment_data/file/184064/DFE$\underline{\text { RR178.pdf }}$

Feniger, Yariv and Adam Lefstein. 2014. 'How not to reason with PISA data: an ironic investigation.' Journal of Education Policy 29(6): 845-55.

Francis, Becky and Louise Archer. 2005. 'British-Chinese pupils' and parents' constructions of the value of education'. British Educational Research Journal 31(1): 89-108.

Fu, Alyssa and Hazel Markus. 2014. 'My mother and me: why tiger mothers motivate Asian Americans but not European Americans'. Personality and Social Psychology Bulletin 40(6): 739-49.

Ganzeboom, Harry and Donald Treiman. 1996. 'Internationally comparable measures of occupational status for the 1988 international standard classification of occupations.' Social Science Research 25: 201-239. 
Jerrim, John and Alvaro Choi. 2014. 'The mathematics skills of school children: how does the UK compare to the high performing East Asian nations?' Journal of Education Policy 29(3): 349-76.

Kim, Kyung. 2005. 'Learning from each other: creativity in East Asian and American education'. Creativity Research Journal 17(4): 337-47.

Leung, Fredrick. 2006. 'Mathematics education in East Asia and the West: does culture matter?' Pp. 21-46 in Mathematics Education in Different Cultural Traditions-A Comparative Study of East Asia and the West. Edited by Fredrick Leung, Klaus-D. Graf and Francis Lopez-Real. Springer.

Lynn, Richard and Gerhard Meisenberg. 2010. 'National IQs calculated and validated for 108 nations'. Intelligence 38(4):353-60.

Micklewright, John; John Jerrim.; Anna Vignoles; Andrew Jenkins; Rebecca Allen; Sonia Llie; Elodie Bellarbre; Fabian Barrera and Christopher Hein. 2014. 'Teachers in secondary schools: evidence from TALIS 2013'. Department for Education Research Report DFERR302. London (England): Department for Education. Accessed 22/07/2014 from https://www.gov.uk/government/publications/teachers-in-secondary-schools-evidence-fromtalis-2013

OECD. 2009. 'Analysis with plausible values'. DOI 10.1787/9789264056275-9-en

OECD. 2010. 'PISA 2009 results. Learning to learn: student engagement strategies and practices'. Paris: OECD.

OECD. 2013. 'Asian countries top OECD's latest PISA survey on state of global education'. Accessed 22/07/2014 from http://www.oecd.org/education/asian-countries-top-oecd-s-latestpisa-survey-on-state-of-global-education.htm

OECD. 2014 (Forthcoming). 'PISA 2012 technical report'. Paris: OECD.

Ryan, Chris. 2013. 'What is behind the decline in student achievement in Australia?' Economics of Education Review 37: 226-39.

Strand, Steve. 2010. 'Do some schools narrow the gap? Differential school effectiveness by ethnicity, gender, poverty and prior attainment'. School Effectiveness and School Improvement 21(3): 289-314.

Strand, Steve. 2014. 'School effects and ethnic, gender and socio-economic gaps in educational achievement at age 11'. Oxford Review of Education 40(2): 223-245.

The Economist. 2014. 'Evaluating Shanghai's high test scores'. Accessed 22/07/2014 from http://www.economist.com/blogs/analects/2014/01/chinese$\underline{\text { schools?fsrc }=\mathrm{scn} / \mathrm{tw} \text { ec/evaluating_shanghais_high_test_scores }}$

Time Magazine. 2013. 'China is cheating the world student rankings system'. Accessed 22/07/2014 from http://world.time.com/2013/12/04/china-is-cheating-the-world-studentrankings-system/ 
Tucker, Marc. 2011. 'Surpassing Shanghai: an agenda for American education built on the world's leading systems'. Harvard Education Publishing Group: Harvard.

Uttal, David. 1997. 'Beliefs about genetic influences on mathematics achievement: a crosscultural comparison'. Genetica 99(2):165-72.

Wu, Margaret and Dianzhou Zhang. 2006. 'An overview of the mathematics curricula in the West and East'. Pp. 181-193 in Mathematics Education in Different Cultural Traditions-A Comparative Study of East Asia and the West. Edited by Fredrick Leung, Klaus-D. Graf and Francis Lopez-Real. Springer. 
Table 1a. The demographic characteristics of Australian natives compared to second-generation East Asian immigrants

\begin{tabular}{|c|c|c|c|c|c|}
\hline & \multirow{2}{*}{$\begin{array}{c}\text { Natives } \\
\text { Australian }\end{array}$} & \multicolumn{4}{|c|}{ Second-generation immigrants: parental origin } \\
\hline & & $\begin{array}{c}\text { High-performing } \\
\text { East Asian }\end{array}$ & $\begin{array}{l}\text { Low-performing } \\
\text { East Asian }\end{array}$ & $\begin{array}{l}\text { Indian } \\
\text { region }\end{array}$ & $\begin{array}{c}\text { United } \\
\text { Kingdom }\end{array}$ \\
\hline \multicolumn{6}{|l|}{ Gender } \\
\hline$\%$ Female & 49 & 44 & 50 & 52 & 48 \\
\hline$\%$ Male & 51 & 56 & 50 & 48 & 52 \\
\hline \multicolumn{6}{|l|}{ Mother's education } \\
\hline$\%$ ISCED $0-2$ & 21 & 13 & 17 & 13 & 20 \\
\hline$\%$ ISCED 3 - 4 & 35 & 29 & 34 & 34 & 31 \\
\hline$\%$ ISCED $5 b$ & 13 & 11 & 11 & 7 & 15 \\
\hline$\%$ ISCED 5a+ & 28 & 47 & 37 & 43 & 32 \\
\hline \multicolumn{6}{|l|}{ Father's education } \\
\hline$\%$ ISCED 0 - 2 & 25 & 15 & 20 & 1 & 18 \\
\hline$\%$ ISCED 3 - 4 & 38 & 25 & 35 & 23 & 39 \\
\hline$\%$ ISCED $5 b$ & 9 & 8 & 8 & 5 & 9 \\
\hline$\%$ ISCED $5 \mathrm{a}+$ & 25 & 51 & 37 & 69 & 32 \\
\hline \multicolumn{6}{|l|}{ Mother's occupation (ISEI) } \\
\hline Mean & 52 & 50 & 48 & 52 & 53 \\
\hline \multicolumn{6}{|l|}{ Father's occupation (ISEI) } \\
\hline Mean & 46 & 50 & 46 & 58 & 49 \\
\hline \multicolumn{6}{|l|}{ Wealth } \\
\hline Mean (standardised) & 0.08 & -0.22 & -0.22 & -0.04 & 0.13 \\
\hline \multicolumn{6}{|l|}{ Language spoken at home } \\
\hline$\%$ English & 100 & 48 & 85 & 73 & 98 \\
\hline$\%$ Other & 0 & 52 & 15 & 27 & 2 \\
\hline \multicolumn{6}{|l|}{ State } \\
\hline$\%$ Australian Capital Territory & 2 & 2 & 2 & 3 & 2 \\
\hline$\%$ Victoria & 30 & 57 & 46 & 53 & 24 \\
\hline$\%$ New South Wales & 25 & 23 & 22 & 28 & 19 \\
\hline$\%$ Queensland & 22 & 10 & 12 & 5 & 19 \\
\hline$\%$ South Australia & 8 & 2 & 4 & 3 & 12 \\
\hline$\%$ Western Australia & 9 & 6 & 12 & 6 & 22 \\
\hline$\%$ Tasmania & 3 & 0 & 1 & 1 & 2 \\
\hline$\%$ Northern Territory & 1 & 1 & 1 & 1 & 1 \\
\hline \multicolumn{6}{|l|}{ Family Structure } \\
\hline$\%$ Single parent & 13 & 12 & 15 & 11 & 13 \\
\hline$\%$ Two parent & 87 & 88 & 85 & 89 & 87 \\
\hline Observations & 6,837 & 276 & 279 & 99 & 1,049 \\
\hline
\end{tabular}

Notes: Author's calculations using the PISA 2012 database. Mother's and father's occupation measured using the International Socio-Economic Index (ISEI), which has a mean of approximately 50 and standard deviation of approximately 22 in Australia. The wealth index has been standardised by the survey organisers across countries. In Australia, the wealth index has a mean of approximately 0.55 and a standard deviation of 1. International Standard Classification of Education (ISCED) Level 0-2 is equivalent to less than upper secondary education. ISCED Level 3-4 refers to upper-secondary but non-tertiary education. ISCED 
Level 5b indicates tertiary education below bachelor's degree. ISCED Level 5a+ is a bachelor's degree or higher. 
Table 1b. PISA scale scores for Australian natives compared to second-generation East Asian immigrants

\begin{tabular}{|c|c|c|c|c|c|c|}
\hline \multirow[b]{2}{*}{ Scale } & \multirow[b]{2}{*}{ Metric } & \multirow{2}{*}{$\begin{array}{c}\text { Natives } \\
\text { Australian }\end{array}$} & \multicolumn{4}{|c|}{ Second-generation immigrants - parental origin } \\
\hline & & & $\begin{array}{c}\text { High-performing } \\
\text { East Asian }\end{array}$ & $\begin{array}{c}\text { Low-performing } \\
\text { East Asian } \\
\end{array}$ & $\begin{array}{l}\text { Indian } \\
\text { region }\end{array}$ & $\begin{array}{c}\text { United } \\
\text { Kingdom }\end{array}$ \\
\hline Difference in test effort & Mean (standardised) & -0.02 & 0.09 & -0.03 & -0.06 & 0.03 \\
\hline Out of school tuition & Mean (weekly hours) & 9 & 15 & 11 & 16 & 9 \\
\hline Work ethic scale & Mean (standardised) & -0.07 & 0.33 & -0.03 & 0.50 & -0.06 \\
\hline Perceived control scale & Mean (standardised) & -0.06 & 0.42 & 0.06 & 0.45 & -0.01 \\
\hline Reasons for failure scale & Mean (standardised) & 0.02 & -0.27 & 0.06 & -0.18 & 0.02 \\
\hline Perseverance & Mean (standardised) & -0.06 & 0.02 & -0.06 & 0.54 & -0.01 \\
\hline Subjective norms & Mean (standardised) & -0.12 & 0.43 & 0.22 & 0.51 & -0.15 \\
\hline Instrumental motivation & Mean (standardised) & -0.04 & 0.15 & 0.14 & 0.24 & -0.01 \\
\hline Attitude school & Mean (standardised) & -0.03 & -0.02 & 0.04 & 0.21 & 0.02 \\
\hline Maths behaviour & Mean (standardised) & -0.13 & 0.67 & 0.35 & 0.57 & -0.18 \\
\hline Expect university & Percentage & 58 & 94 & 81 & 85 & 63 \\
\hline \multicolumn{2}{|c|}{ Unweighted n } & 6,837 & 276 & 279 & 99 & 1,049 \\
\hline
\end{tabular}

Notes: Author's calculations using the PISA 2012 database. Standardised scales have a mean of 0 and a standard deviation of 1 across the Australian population. Figures reported for only those children with valid responses. See Appendix B for the questions that form each scale, and the distribution of responses to one of these questions. 
Table 2. Regression results: Controlling for demographic characteristics and school fixed effects

\begin{tabular}{|c|c|c|c|c|c|c|}
\hline & \multicolumn{2}{|c|}{ Model 1 } & \multicolumn{2}{|c|}{ Model 2} & \multicolumn{2}{|c|}{ Model 3} \\
\hline & $\beta$ & SE & $\beta$ & SE & $\beta$ & SE \\
\hline \multicolumn{7}{|l|}{ Group (Ref: Native Australian) } \\
\hline Second-generation East Asian (HP) & 1.022 & 0.104 & 0.841 & 0.096 & 0.407 & 0.066 \\
\hline Second-generation East Asian (LP) & 0.257 & 0.086 & 0.196 & 0.080 & 0.088 & 0.061 \\
\hline Second-generation Indian & 0.387 & 0.130 & 0.131 & 0.113 & 0.069 & 0.100 \\
\hline Second-generation UK & 0.083 & 0.036 & 0.000 & 0.033 & -0.004 & 0.033 \\
\hline Demographic controls & - & - & $\sqrt{ }$ & $\sqrt{ }$ & $\sqrt{ }$ & $\sqrt{ }$ \\
\hline School fixed effects & - & - & - & - & $\sqrt{ }$ & $\sqrt{ }$ \\
\hline $\mathbf{n}$ & \multicolumn{2}{|c|}{8,539} & \multicolumn{2}{|c|}{8,539} & \multicolumn{2}{|c|}{8,539} \\
\hline
\end{tabular}

Notes: Author's calculations using the PISA 2012 dataset. The $\beta$ column provides the estimated difference in PISA maths test scores between native Australians and secondgeneration immigrants. Figures refer to differences in terms of international standard deviations (one can convert this into raw PISA points simply by multiplying $\beta$ by 100). The SE column gives the estimated standard error. Ticks illustrate the controls included in each model. Demographic controls include mother's and father's education, mother's and father's occupation, household wealth (possessions), language spoken at home, state, urban / rural, family structure, gender, indigenous status and pupil age. 
Table 3. Regression results: Adding controls for test effort, time spent studying, work ethic and teacher support

\begin{tabular}{|c|c|c|c|c|c|c|}
\hline & \multicolumn{2}{|c|}{ Model 4} & \multicolumn{2}{|c|}{ Model 5} & \multicolumn{2}{|c|}{ Model 6} \\
\hline & $\boldsymbol{\beta}$ & SE & $\boldsymbol{\beta}$ & SE & $\boldsymbol{\beta}$ & SE \\
\hline \multicolumn{7}{|l|}{ Group (Ref: Native Australian) } \\
\hline Second-generation East Asian (HP) & 0.406 & 0.065 & 0.290 & 0.067 & 0.244 & 0.068 \\
\hline Second-generation East Asian (LP) & 0.088 & 0.062 & 0.060 & 0.057 & 0.033 & 0.055 \\
\hline Second-generation Indian & 0.061 & 0.101 & 0.077 & 0.099 & -0.008 & 0.093 \\
\hline Second-generation UK & -0.003 & 0.032 & -0.013 & 0.032 & -0.012 & 0.031 \\
\hline Demographic controls & $\sqrt{ }$ & $\sqrt{ }$ & $\sqrt{ }$ & $\sqrt{ }$ & $\sqrt{ }$ & $\sqrt{ }$ \\
\hline School fixed effects & $\sqrt{ }$ & $\sqrt{ }$ & $\sqrt{ }$ & $\sqrt{ }$ & $\sqrt{ }$ & $\sqrt{ }$ \\
\hline Effort on PISA & $\sqrt{ }$ & $\sqrt{ }$ & $\sqrt{ }$ & $\sqrt{ }$ & $\sqrt{ }$ & $\sqrt{ }$ \\
\hline Time studying outside school & - & - & $\sqrt{ }$ & $\sqrt{ }$ & $\sqrt{ }$ & $\sqrt{ }$ \\
\hline Work ethic scale & - & - & - & - & $\sqrt{ }$ & $\sqrt{ }$ \\
\hline Perceived control scale & - & - & - & - & $\sqrt{ }$ & $\sqrt{ }$ \\
\hline Attributions to failure scale & - & - & - & - & $\sqrt{ }$ & $\sqrt{ }$ \\
\hline Perseverance & - & - & - & - & $\sqrt{ }$ & $\sqrt{ }$ \\
\hline $\mathbf{n}$ & \multicolumn{2}{|c|}{8,539} & \multicolumn{2}{|c|}{8,539} & \multicolumn{2}{|c|}{8,539} \\
\hline
\end{tabular}

Notes: Author's calculations using the PISA 2012 dataset. See notes to Table 2. 
Table 4. Regression results: Adding controls for subjective norms, instrumental motivation, school attitudes and future aspirations

\begin{tabular}{|c|c|c|c|c|c|c|c|c|}
\hline & \multicolumn{2}{|c|}{ Model 7} & \multicolumn{2}{|c|}{ Model 8} & \multicolumn{2}{|c|}{ Model 9} & \multicolumn{2}{|c|}{ Model 10} \\
\hline & $\boldsymbol{\beta}$ & SE & $\boldsymbol{\beta}$ & SE & $\beta$ & SE & $\boldsymbol{\beta}$ & SE \\
\hline \multicolumn{9}{|l|}{ Group (Ref: Native Australian) } \\
\hline Second-generation East Asian (HP) & 0.247 & 0.068 & 0.259 & 0.066 & 0.202 & 0.064 & 0.148 & 0.063 \\
\hline Second-generation East Asian (LP) & 0.038 & 0.055 & 0.035 & 0.055 & -0.009 & 0.056 & -0.054 & 0.055 \\
\hline Second-generation Indian & -0.009 & 0.093 & -0.005 & 0.093 & -0.049 & 0.092 & -0.057 & 0.090 \\
\hline Second-generation UK & -0.015 & 0.031 & -0.016 & 0.031 & -0.009 & 0.031 & -0.010 & 0.030 \\
\hline Demographic controls & $\sqrt{ }$ & $\sqrt{ }$ & $\sqrt{ }$ & $\sqrt{ }$ & $\sqrt{ }$ & $\sqrt{ }$ & $\sqrt{ }$ & $\sqrt{ }$ \\
\hline School fixed effects & $\sqrt{ }$ & $\sqrt{ }$ & $\sqrt{ }$ & $\sqrt{ }$ & $\sqrt{ }$ & $\sqrt{ }$ & $\sqrt{ }$ & $\sqrt{ }$ \\
\hline Effort on PISA & $\sqrt{ }$ & $\sqrt{ }$ & $\sqrt{ }$ & $\sqrt{ }$ & $\sqrt{ }$ & $\sqrt{ }$ & $\sqrt{ }$ & $\sqrt{ }$ \\
\hline Time studying outside school & $\sqrt{ }$ & $\sqrt{ }$ & $\sqrt{ }$ & $\sqrt{ }$ & $\sqrt{ }$ & $\sqrt{ }$ & $\sqrt{ }$ & $\sqrt{ }$ \\
\hline Work ethic scale & $\sqrt{ }$ & $\sqrt{ }$ & $\sqrt{ }$ & $\sqrt{ }$ & $\sqrt{ }$ & $\sqrt{ }$ & $\sqrt{ }$ & $\sqrt{ }$ \\
\hline Perceived control scale & $\sqrt{ }$ & $\sqrt{ }$ & $\sqrt{ }$ & $\sqrt{ }$ & $\sqrt{ }$ & $\sqrt{ }$ & $\sqrt{ }$ & $\sqrt{ }$ \\
\hline Attributions to failure scale & $\sqrt{ }$ & $\sqrt{ }$ & $\sqrt{ }$ & $\sqrt{ }$ & $\sqrt{ }$ & $\sqrt{ }$ & $\sqrt{ }$ & $\sqrt{ }$ \\
\hline Perseverance & $\sqrt{ }$ & $\sqrt{ }$ & $\sqrt{ }$ & $\sqrt{ }$ & $\sqrt{ }$ & $\sqrt{ }$ & $\sqrt{ }$ & $\sqrt{ }$ \\
\hline Subjective norms scale & $\sqrt{ }$ & $\sqrt{ }$ & $\sqrt{ }$ & $\sqrt{ }$ & $\sqrt{ }$ & $\sqrt{ }$ & $\sqrt{ }$ & $\sqrt{ }$ \\
\hline Instrumental motivation scale & - & - & $\sqrt{ }$ & $\sqrt{ }$ & $\sqrt{ }$ & $\sqrt{ }$ & $\sqrt{ }$ & $\sqrt{ }$ \\
\hline Attitudes towards school scale & - & - & $\sqrt{ }$ & $\sqrt{ }$ & $\sqrt{ }$ & $\sqrt{ }$ & $\sqrt{ }$ & $\sqrt{ }$ \\
\hline Maths behaviour scales & - & - & - & - & $\sqrt{ }$ & $\sqrt{ }$ & $\sqrt{ }$ & $\sqrt{ }$ \\
\hline Future aspirations & - & - & - & - & - & - & $\sqrt{ }$ & $\sqrt{ }$ \\
\hline n & \multicolumn{2}{|c|}{8,539} & \multicolumn{2}{|c|}{8,539} & \multicolumn{2}{|c|}{8,539} & \multicolumn{2}{|c|}{8,539} \\
\hline
\end{tabular}

Notes: Author's calculations using the PISA 2012 dataset. See notes to Table 2. 
Figure 1. The PISA effort thermometer

How much effort did you invest?

Please try to imagine an actual situation (at school or in some other context) that is highly important to you personally, so that you would try your very best and put in as much effort as you could to do well.

In this situation you would mark the highest value on the "effort thermometer" as shown below:
Compared to the situation you have just imagined, how much effort did you put into doing this test?
How much effort would you have invested if your marks from the test were going to be counted in your school marks?

$\begin{array}{llllll}X & 10 & \square & 10 & \square & 10 \\ \square & 9 & \square & 9 & \square & 9 \\ \square & 8 & \square & 8 & \square & 8 \\ \square & 7 & \square & 7 & \square & 7 \\ \square & 6 & \square & 6 & \square & 6 \\ \square & 5 & \square & 5 & \square & 5 \\ \square & 4 & \square & 4 & \square & 4 \\ \square & 3 & \square & 3 & \square & 3 \\ \square & 2 & \square & 2 & \square & 2 \\ \square & 1 & \square & 1 & \square & 1\end{array}$

Source: Butler and Adams (2007: Figure 1) 
Figure 2. Average PISA maths test scores: a comparison of second-generation Australian immigrants to children in other countries

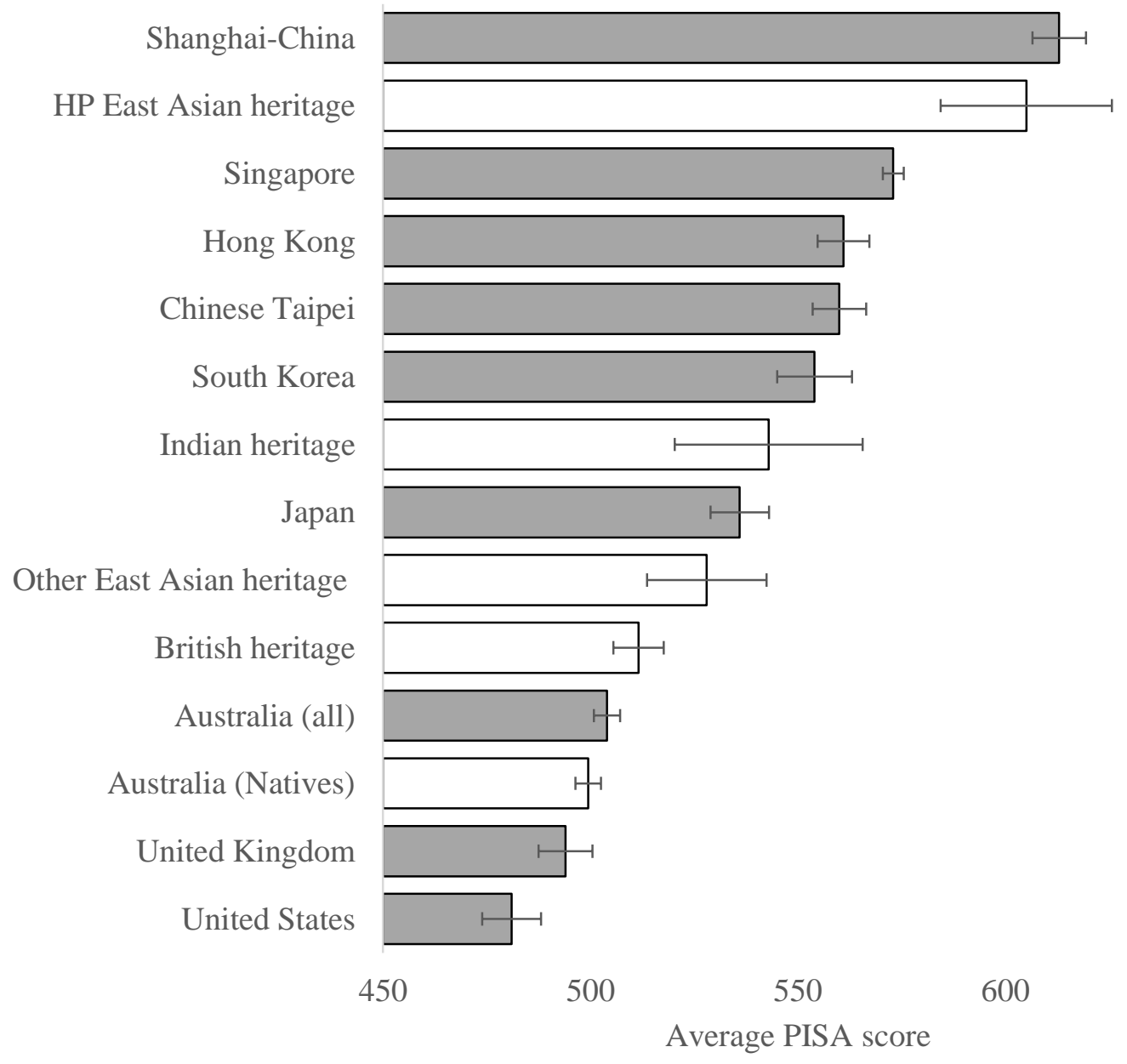

Notes: Author's calculations using the Australian PISA 2012 data. Grey bars illustrate average PISA maths test score for whole countries / economies. White bars illustrate average PISA maths scores for Australian sub-groups of interest. "HP East Asian heritage" refers to estimates for second-generation immigrants whose parents were born in a high-performing East Asian country. The thin black line running through the centre of bars refer to the estimated 95 percent confidence interval. 
Figure 3. Differences in mean PISA maths test scores between Australian natives and second-generation immigrants from high-performing East Asian countries: trends over time

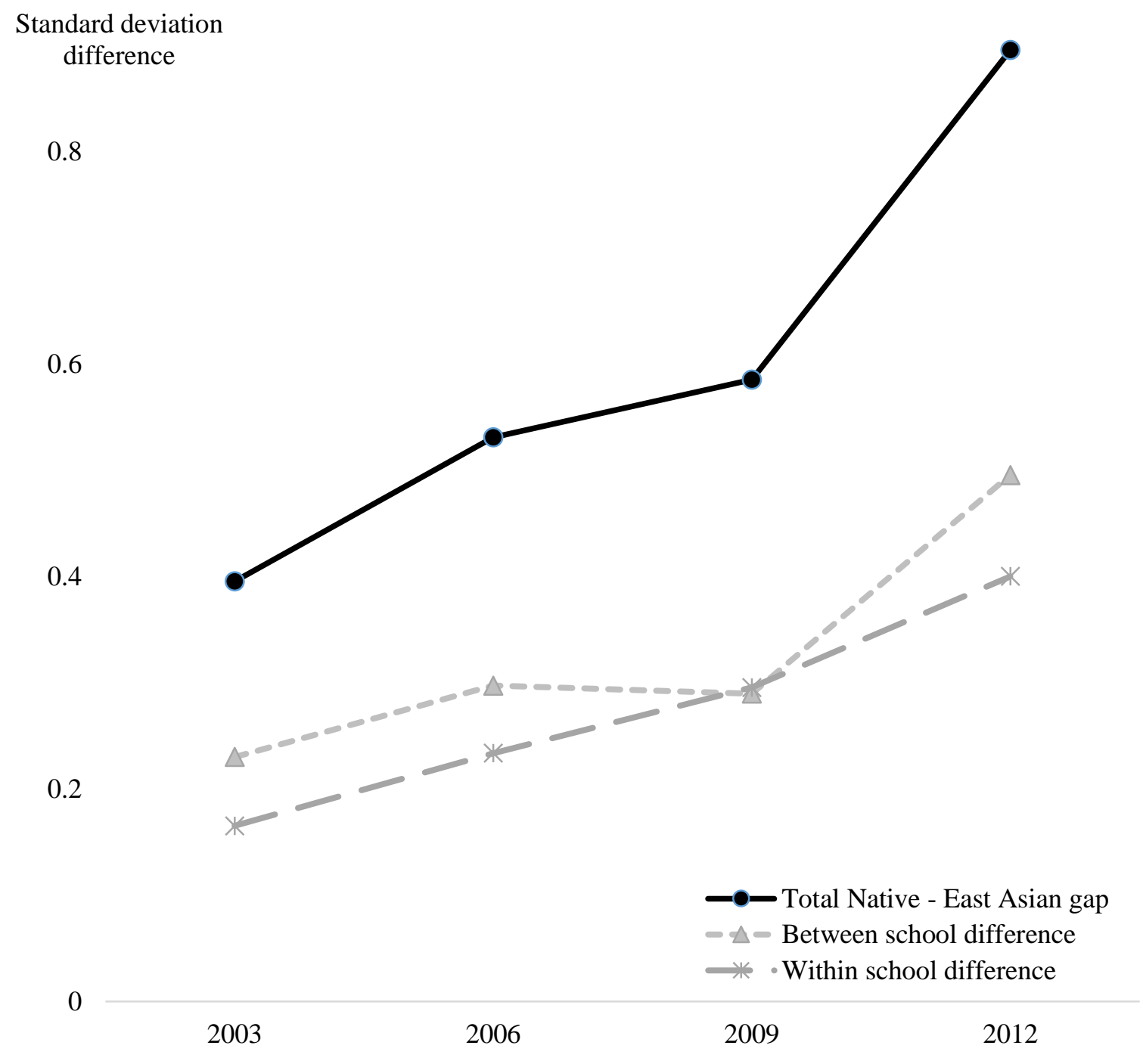

Notes: Author's calculations using the PISA 2003, 2006, 2009 and 2012 datasets.

Figures on the vertical axis refer to standard deviation differences between the native and second-generation East Asian immigrant groups. Black line where only basic demographic characteristics are included in the model. Dashed grey line with star markers where a school level fixed effect has been added. All linear trends presented are statistically significant at the five percent level. 


\section{Appendix A. Alternative methods for handling missing data}

The results presented in the main body of the paper used Multiple Imputation by Chained Equations (MICE) to account for the "rotated block design" of the PISA 2012 background questionnaire. Recall that this meant some of the variables included in Models 5 to 10 were Missing Completely At Random (MCAR). This appendix presents alternative estimates where this missing data issue is tackled in a different way.

First, estimates are presented from a "complete case" analysis. This is where the sample is restricted to 2,143 observations where complete information is available on all variables. These estimates have the advantage of using observed information only, but comes at the sacrifice of losing statistical power. Moreover, some of the variables that were included in the main analysis (e.g. the work ethic and reasons for failure scales) cannot be included as these 2,143 children did not respond to these particular questions. (Again, this was simply due to the rotated questionnaire design, and not refusal to respond).

Parameter estimates can be found in Appendix Tables A1 to A3. These results are analogous to those presented in Tables 2, 3 and 4 in the main body of the paper. Most of the substantive conclusions reached continue to hold. For instance, the unconditional estimates (model 1) continue to show an extremely large gap (1.09 standard deviations) between the native Australian and second-generation East Asian immigrant groups. This declines to 0.96 standard deviations once demographic controls have been added (model 2) and down to 0.29 with the inclusion of a school level fixed effect (model 3). Moreover, there continues to be non-trivial differences in maths achievement between Australian natives and secondgeneration East Asian children, even when they share the same demographic characteristics and attend the same school. Controlling for effort on the PISA test (model 4) continues to make little difference, though there is a notable drop (down to 0.25 standard deviations) when out-of-school study time has been taken into account (model 5). In contrast to the results presented in the main body of the paper, the parameter estimate does not change between model 5 and model 6. However, this is likely to be due to the more limited selection of variables now included in the model ${ }^{23}$. There is then little change to the results until model 10, when educational aspirations are added to the model (with the native-East Asian parameter estimate falling slightly from approximately 0.25 to 0.22 ). Again, this is broadly in-line with the results obtained using multiple imputation.

\section{$<$ Appendix Tables A1 to A3 >>}

\footnotetext{
${ }^{23}$ Due to the rotated design, only the perseverance scale can be included in the complete case version of model 6 . In contrast, the work ethic, attributions to failure and perceived control scales were also included in the sixth specification when using multiple imputation (in the main body of the paper).
} 
The second alternative method is to include missing dummy variables in the model where pieces of information are not available. This has the advantage of retaining all available observations in the analysis (i.e. $\mathrm{n}=8,539$ rather than 2,143 in the complete case analysis) while also allowing all variables of interest to be included in the model (i.e. unlike the complete case analysis the work ethic, reasons for failure, perceived control and attitudes towards school scales no longer need to be dropped). The disadvantage over multiple imputation is that this is a less principled way of accounting for missing data. In particular, it could potentially lead to underestimation of the reduction in the second-generation immigrant parameter estimates when additional factors are added to the model. These estimates are presented in Appendix Tables A4 to A6. Appendix Table A7 then provides a comparison of the high-performing East Asian parameter estimates across the three different methods used to account for missing data.

\section{<< Appendix Tables A4 to A7 >>}

Reassuringly, the magnitude and pattern of coefficient estimates are similar across the different sets of estimates. The only slight discrepancy between the "multiple imputation" and "missing dummies" results are for model 6 and model 9. In particular, the missing dummy method results suggest that that the study hours outside of school and the "maths behaviour" scale explain slightly less of the remaining East Asian-native gap than the multiple imputation results. Nevertheless, the overall message stemming from this appendix is that substantive findings are quite robust to the different ways of handling missing data and the rotated PISA questionnaire design. 
Appendix Table A1. Complete case analysis. Regression models 1-3

\begin{tabular}{lccccccc}
\hline & \multicolumn{2}{c}{ Model 1 } & \multicolumn{2}{c}{ Model 2 } & \multicolumn{2}{c}{ Model 3 } \\
& $\boldsymbol{\beta}$ & $\mathbf{S E}$ & $\boldsymbol{\beta}$ & $\mathbf{S E}$ & $\boldsymbol{\beta}$ & SE \\
\hline Group (Ref: Native Australian) & & & & & & \\
\hline Second-generation East Asian (HP) & 1.087 & 0.148 & 0.956 & 0.126 & 0.292 & 0.133 \\
Second-generation East Asian (LP) & 0.362 & 0.153 & 0.230 & 0.150 & 0.077 & 0.134 \\
Second-generation Indian & 0.416 & 0.225 & 0.110 & 0.221 & -0.073 & 0.268 \\
Second-generation UK & 0.050 & 0.068 & -0.047 & 0.062 & 0.039 & 0.074 \\
Demographic controls & - & - & $\sqrt{ }$ & $\sqrt{ }$ & $\sqrt{ }$ & $\sqrt{ }$ \\
School fixed effects & - & - & - & - & $\sqrt{ }$ & $\sqrt{ }$ \\
\hline $\mathbf{N}$ & \multicolumn{2}{c}{$\mathbf{2 , 1 4 3}$} & \multicolumn{3}{c}{$\mathbf{2 , 1 4 3}$} & \multicolumn{2}{c}{$\mathbf{2 , 1 4 3}$} \\
\hline
\end{tabular}

Appendix Table A2. Complete case analysis. Regression models 4-6

\begin{tabular}{|c|c|c|c|c|c|c|}
\hline & \multicolumn{2}{|c|}{ Model 4} & \multicolumn{2}{|c|}{ Model 5} & \multicolumn{2}{|c|}{ Model 6} \\
\hline & B & SE & $\boldsymbol{\beta}$ & SE & $\boldsymbol{\beta}$ & SE \\
\hline \multicolumn{7}{|l|}{ Group (Ref: Native Australian) } \\
\hline Second-generation East Asian (HP) & 0.293 & 0.130 & 0.246 & 0.129 & 0.251 & 0.128 \\
\hline Second-generation East Asian (LP) & 0.077 & 0.137 & 0.074 & 0.139 & 0.109 & 0.130 \\
\hline Second-generation Indian & -0.081 & 0.282 & -0.076 & 0.289 & -0.095 & 0.263 \\
\hline Second-generation UK & 0.056 & 0.073 & 0.058 & 0.073 & 0.068 & 0.068 \\
\hline Demographic controls & $\sqrt{ }$ & $\sqrt{ }$ & $\sqrt{ }$ & $\sqrt{ }$ & $\sqrt{ }$ & $\sqrt{ }$ \\
\hline School fixed effects & $\sqrt{ }$ & $\sqrt{ }$ & $\sqrt{ }$ & $\sqrt{ }$ & $\sqrt{ }$ & $\sqrt{ }$ \\
\hline Effort on PISA & $\sqrt{ }$ & $\sqrt{ }$ & $\sqrt{ }$ & $\sqrt{ }$ & $\sqrt{ }$ & $\sqrt{ }$ \\
\hline Time studying outside school & - & - & $\sqrt{ }$ & $\sqrt{ }$ & $\sqrt{ }$ & $\sqrt{ }$ \\
\hline Perseverance & - & - & - & - & $\sqrt{ }$ & $\sqrt{ }$ \\
\hline $\mathbf{N}$ & \multicolumn{2}{|c|}{2,143} & \multicolumn{2}{|c|}{2,143} & \multicolumn{2}{|c|}{2,143} \\
\hline
\end{tabular}


Appendix Table A3. Complete case analysis. Regression models 7-10

\begin{tabular}{|c|c|c|c|c|c|c|c|c|}
\hline & \multicolumn{2}{|c|}{ Model 7} & \multicolumn{2}{|c|}{ Model 8} & \multicolumn{2}{|c|}{ Model 9} & \multicolumn{2}{|c|}{ Model 10} \\
\hline & $\boldsymbol{\beta}$ & SE & $\beta$ & SE & $\boldsymbol{\beta}$ & SE & $\boldsymbol{\beta}$ & SE \\
\hline \multicolumn{9}{|l|}{ Group (Ref: Native Australian) } \\
\hline Second-generation East Asian (HP) & 0.255 & 0.122 & 0.259 & 0.123 & 0.247 & 0.125 & 0.223 & 0.121 \\
\hline Second-generation East Asian (LP) & 0.108 & 0.134 & 0.069 & 0.133 & 0.035 & 0.131 & -0.047 & 0.123 \\
\hline Second-generation Indian & -0.107 & 0.261 & -0.064 & 0.262 & -0.113 & 0.269 & -0.052 & 0.243 \\
\hline Second-generation UK & 0.070 & 0.069 & 0.066 & 0.069 & 0.057 & 0.066 & 0.018 & 0.063 \\
\hline Demographic controls & $\sqrt{ }$ & $\sqrt{ }$ & $\sqrt{ }$ & $\sqrt{ }$ & $\sqrt{ }$ & $\sqrt{ }$ & $\sqrt{ }$ & $\sqrt{ }$ \\
\hline School fixed effects & $\sqrt{ }$ & $\sqrt{ }$ & $\sqrt{ }$ & $\sqrt{ }$ & $\sqrt{ }$ & $\sqrt{ }$ & $\sqrt{ }$ & $\sqrt{ }$ \\
\hline Effort on PISA & $\sqrt{ }$ & $\sqrt{ }$ & $\sqrt{ }$ & $\sqrt{ }$ & $\sqrt{ }$ & $\sqrt{ }$ & $\sqrt{ }$ & $\sqrt{ }$ \\
\hline Time studying outside school & $\sqrt{ }$ & $\sqrt{ }$ & $\sqrt{ }$ & $\sqrt{ }$ & $\sqrt{ }$ & $\sqrt{ }$ & $\sqrt{ }$ & $\sqrt{ }$ \\
\hline Perseverance & $\sqrt{ }$ & $\sqrt{ }$ & $\sqrt{ }$ & $\sqrt{ }$ & $\sqrt{ }$ & $\sqrt{ }$ & $\sqrt{ }$ & $\sqrt{ }$ \\
\hline Subjective norms scale & $\sqrt{ }$ & $\sqrt{ }$ & $\sqrt{ }$ & $\sqrt{ }$ & $\sqrt{ }$ & $\sqrt{ }$ & $\sqrt{ }$ & $\sqrt{ }$ \\
\hline Instrumental motivation scale & - & - & $\sqrt{ }$ & $\sqrt{ }$ & $\sqrt{ }$ & $\sqrt{ }$ & $\sqrt{ }$ & $\sqrt{ }$ \\
\hline Maths behaviour scales & - & - & - & - & $\sqrt{ }$ & $\sqrt{ }$ & $\sqrt{ }$ & $\sqrt{ }$ \\
\hline Future aspirations & - & - & - & - & - & - & $\sqrt{ }$ & $\sqrt{ }$ \\
\hline $\mathbf{N}$ & \multicolumn{2}{|c|}{2,143} & \multicolumn{2}{|c|}{2,143} & \multicolumn{2}{|c|}{2,141} & \multicolumn{2}{|c|}{2,141} \\
\hline
\end{tabular}


Appendix Table A4. "Missing" dummy variables analysis. Regression models 1-3

\begin{tabular}{|c|c|c|c|c|c|c|}
\hline & \multicolumn{2}{|c|}{ Model 1} & \multicolumn{2}{|c|}{ Model 2} & \multicolumn{2}{|c|}{ Model 3} \\
\hline & $\boldsymbol{\beta}$ & SE & $\beta$ & SE & $\boldsymbol{\beta}$ & SE \\
\hline \multicolumn{7}{|l|}{ Group (Ref: Native Australian) } \\
\hline Second-generation East Asian (HP) & 1.020 & 0.102 & 0.840 & 0.091 & 0.412 & 0.064 \\
\hline Second-generation East Asian (LP) & 0.260 & 0.084 & 0.192 & 0.077 & 0.087 & 0.059 \\
\hline Second-generation Indian & 0.397 & 0.127 & 0.130 & 0.106 & 0.066 & 0.094 \\
\hline Second-generation UK & 0.081 & 0.035 & 0.006 & 0.031 & 0.000 & 0.031 \\
\hline Demographic controls & - & - & $\sqrt{ }$ & $\sqrt{ }$ & $\sqrt{ }$ & $\sqrt{ }$ \\
\hline School fixed effects & - & - & - & - & $\sqrt{ }$ & $\sqrt{ }$ \\
\hline$\underline{n}$ & \multicolumn{2}{|c|}{8,541} & \multicolumn{2}{|c|}{8,541} & \multicolumn{2}{|c|}{8,541} \\
\hline
\end{tabular}


Appendix Table A5. "Missing" dummy variables analysis. Regression models 4-6

\begin{tabular}{|c|c|c|c|c|c|c|}
\hline & \multicolumn{2}{|c|}{ Model 4} & \multicolumn{2}{|c|}{ Model 5} & \multicolumn{2}{|c|}{ Model 6} \\
\hline & $\beta$ & SE & $\beta$ & SE & $\beta$ & SE \\
\hline \multicolumn{7}{|l|}{ Group (Ref: Native Australian) } \\
\hline Second-generation East Asian (HP) & 0.404 & 0.063 & 0.357 & 0.064 & 0.297 & 0.061 \\
\hline Second-generation East Asian (LP) & 0.092 & 0.059 & 0.099 & 0.055 & 0.109 & 0.053 \\
\hline Second-generation Indian & 0.058 & 0.093 & 0.089 & 0.091 & 0.027 & 0.089 \\
\hline Second-generation UK & 0.000 & 0.031 & -0.005 & 0.030 & -0.001 & 0.028 \\
\hline Demographic controls & $\sqrt{ }$ & $\sqrt{ }$ & $\sqrt{ }$ & $\sqrt{ }$ & $\sqrt{ }$ & $\sqrt{ }$ \\
\hline School fixed effects & $\sqrt{ }$ & $\sqrt{ }$ & $\sqrt{ }$ & $\sqrt{ }$ & $\sqrt{ }$ & $\sqrt{ }$ \\
\hline Effort on PISA & $\sqrt{ }$ & $\sqrt{ }$ & $\sqrt{ }$ & $\sqrt{ }$ & $\sqrt{ }$ & $\sqrt{ }$ \\
\hline Time studying outside school & - & - & $\sqrt{ }$ & $\sqrt{ }$ & $\sqrt{ }$ & $\sqrt{ }$ \\
\hline Work ethic scale & - & - & - & - & $\sqrt{ }$ & $\sqrt{ }$ \\
\hline Perceived control scale & - & - & - & - & $\sqrt{ }$ & $\sqrt{ }$ \\
\hline Attributions to failure scale & - & - & - & - & $\sqrt{ }$ & $\sqrt{ }$ \\
\hline Perseverance & - & - & - & - & $\sqrt{ }$ & $\sqrt{ }$ \\
\hline $\bar{n}$ & \multicolumn{2}{|c|}{8,541} & \multicolumn{2}{|c|}{8,541} & \multicolumn{2}{|c|}{8,541} \\
\hline
\end{tabular}


Appendix Table A6. "Missing" dummy variables analysis. Regression models 7-10

\begin{tabular}{|c|c|c|c|c|c|c|c|c|}
\hline & \multicolumn{2}{|c|}{ Model 7} & \multicolumn{2}{|c|}{ Model 8} & \multicolumn{2}{|c|}{ Model 9} & \multicolumn{2}{|c|}{ Model 10} \\
\hline & $\beta$ & SE & $\beta$ & SE & $\beta$ & SE & $\beta$ & SE \\
\hline \multicolumn{9}{|l|}{ Group (Ref: Native Australian) } \\
\hline Second-generation East Asian (HP) & 0.285 & 0.061 & 0.294 & 0.061 & 0.273 & 0.060 & 0.213 & 0.059 \\
\hline Second-generation East Asian (LP) & 0.111 & 0.053 & 0.102 & 0.053 & 0.082 & 0.053 & 0.026 & 0.053 \\
\hline Second-generation Indian & 0.027 & 0.090 & 0.025 & 0.088 & 0.007 & 0.088 & -0.012 & 0.086 \\
\hline Second-generation UK & -0.003 & 0.028 & -0.001 & 0.028 & 0.002 & 0.027 & -0.001 & 0.026 \\
\hline Demographic controls & $\sqrt{ }$ & $\sqrt{ }$ & $\sqrt{ }$ & $\sqrt{ }$ & $\sqrt{ }$ & $\sqrt{ }$ & $\sqrt{ }$ & $\sqrt{ }$ \\
\hline School fixed effects & $\sqrt{ }$ & $\sqrt{ }$ & $\sqrt{ }$ & $\sqrt{ }$ & $\sqrt{ }$ & $\sqrt{ }$ & $\sqrt{ }$ & $\sqrt{ }$ \\
\hline Effort on PISA & $\sqrt{ }$ & $\sqrt{ }$ & $\sqrt{ }$ & $\sqrt{ }$ & $\sqrt{ }$ & $\sqrt{ }$ & $\sqrt{ }$ & $\sqrt{ }$ \\
\hline Time studying outside school & $\sqrt{ }$ & $\sqrt{ }$ & $\sqrt{ }$ & $\sqrt{ }$ & $\sqrt{ }$ & $\sqrt{ }$ & $\sqrt{ }$ & $\sqrt{ }$ \\
\hline Work ethic scale & $\sqrt{ }$ & $\sqrt{ }$ & $\sqrt{ }$ & $\sqrt{ }$ & $\sqrt{ }$ & $\sqrt{ }$ & $\sqrt{ }$ & $\sqrt{ }$ \\
\hline Perceived control scale & $\sqrt{ }$ & $\sqrt{ }$ & $\sqrt{ }$ & $\sqrt{ }$ & $\sqrt{ }$ & $\sqrt{ }$ & $\sqrt{ }$ & $\sqrt{ }$ \\
\hline Attributions to failure scale & $\sqrt{ }$ & $\sqrt{ }$ & $\sqrt{ }$ & $\sqrt{ }$ & $\sqrt{ }$ & $\sqrt{ }$ & $\sqrt{ }$ & $\sqrt{ }$ \\
\hline Perseverance & $\sqrt{ }$ & $\sqrt{ }$ & $\sqrt{ }$ & $\sqrt{ }$ & $\sqrt{ }$ & $\sqrt{ }$ & $\sqrt{ }$ & $\sqrt{ }$ \\
\hline Subjective norms scale & $\sqrt{ }$ & $\sqrt{ }$ & $\sqrt{ }$ & $\sqrt{ }$ & $\sqrt{ }$ & $\sqrt{ }$ & $\sqrt{ }$ & $\sqrt{ }$ \\
\hline Instrumental motivation scale & - & - & $\sqrt{ }$ & $\sqrt{ }$ & $\sqrt{ }$ & $\sqrt{ }$ & $\sqrt{ }$ & $\sqrt{ }$ \\
\hline Attitudes towards school scale & - & - & $\sqrt{ }$ & $\sqrt{ }$ & $\sqrt{ }$ & $\sqrt{ }$ & $\sqrt{ }$ & $\sqrt{ }$ \\
\hline Maths behaviour scales & - & - & - & - & $\sqrt{ }$ & $\sqrt{ }$ & $\sqrt{ }$ & $\sqrt{ }$ \\
\hline Future aspirations & - & - & - & - & - & - & $\sqrt{ }$ & $\sqrt{ }$ \\
\hline $\mathbf{n}$ & \multicolumn{2}{|c|}{8,541} & \multicolumn{2}{|c|}{8,541} & \multicolumn{2}{|c|}{8,541} & \multicolumn{2}{|c|}{8,539} \\
\hline
\end{tabular}


Appendix Table A7. A comparison of the high-performing East Asian parameter estimate across different ways of handling missing data

\begin{tabular}{lcccccc}
\hline & \multicolumn{2}{c}{ Multiple imputation } & \multicolumn{2}{c}{ Complete case } & \multicolumn{2}{c}{ Missing dummies } \\
& Beta & SE & Beta & SE & Beta & SE \\
\hline Model 1 & 1.02 & 0.10 & 1.09 & 0.15 & 1.02 & 0.10 \\
Model 2 & 0.84 & 0.10 & 0.96 & 0.13 & 0.84 & 0.09 \\
Model 3 & 0.41 & 0.07 & 0.29 & 0.13 & 0.41 & 0.06 \\
Model 4 & 0.41 & 0.07 & 0.29 & 0.13 & 0.40 & 0.06 \\
Model 5 & 0.29 & 0.07 & 0.25 & 0.13 & 0.35 & 0.06 \\
Model 6 & 0.24 & 0.07 & 0.25 & 0.13 & 0.29 & 0.06 \\
Model 7 & 0.25 & 0.07 & 0.26 & 0.12 & 0.27 & 0.06 \\
Model 8 & 0.26 & 0.07 & 0.26 & 0.12 & 0.28 & 0.06 \\
Model 9 & 0.20 & 0.06 & 0.25 & 0.12 & 0.26 & 0.06 \\
Model 10 & 0.15 & 0.06 & 0.22 & 0.12 & 0.20 & 0.06 \\
\hline Unweighted n & \multicolumn{6}{c}{$\mathbf{8 , 5 3 9}$} \\
\hline
\end{tabular}

Notes: Figures refer to differences in PISA maths test scores between Australian natives and second-generation East Asian immigrants from a high-performing countries. All figures reported in terms of international standard deviations (multiplying figures by 100 gives differences in terms of PISA points). 'Multiple imputation', 'complete case' and 'missing dummies' refer to the method used to account for missing data. Model refers to the regression model specification used (this is to be cross-referenced with Tables 2, 3 and 4). 


\section{Appendix B. The questions forming each PISA scale score}

\section{Work ethic scale}

I finish my homework in time for mathematics class

I work hard on my mathematics homework

I am prepared for my mathematics exams

I study hard for mathematics quizzes

I keep studying until I understand mathematics material

I pay attention in mathematics class

I listen in mathematics class

I avoid distractions when I am studying mathematics

I keep my mathematics work well organised

\section{Perceived control scale}

If I put in enough effort I can succeed in mathematics

Whether or not I do well in mathematics is completely up to me

Family demands or other problems prevent me from putting a lot of time into my mathematics work

If I had different teachers, I would try harder in mathematics

If I wanted to, I could do well in mathematics

I do badly in mathematics whether or not I study for my exams

\section{Reasons for failure scale}

I'm not very good at solving mathematics problems

My teacher did not explain the concepts well this week

This week I made bad guesses on the quiz

Sometimes the course material is too hard

The teacher did not get students interested in the material

Sometimes I am just unlucky

\section{Perseverance}

When confronted with a problem, I give up easily

I put off difficult problems

I remain interested in the tasks that I start

I continue working on tasks until everything is perfect

When confronted with a problem, I do more than what is expected of me 


\section{Subjective norms}

Most of my friends do well in mathematics

Most of my friends work hard at mathematics

My friends enjoy taking mathematics tests

My parents believe it's important for me to study mathematics

My parents believe that mathematics is important for my career

My parents like mathematics

\section{Instrumental motivation}

Making an effort in mathematics is worth it because it will help me in the work that I want to do later on.

Learning mathematics is worthwhile for me because it will improve my career prospects

Mathematics is an important subject for me because I need it for what I want to study later on

I will learn many things in mathematics that will help me get a job

\section{Attitude school}

School has done little to prepare me for adult life when I leave school

School has been a waste of time

School has helped give me confidence to make decisions

School has taught me things which could be useful in a job

Trying hard at school will help me get a good job

Trying hard at school will help me get into a good college

I enjoy receiving good grades

Trying hard at school is important

\section{Maths behaviour}

I talk about mathematics problems with my friends

I help my friends with mathematics

I do mathematics as an extracurricular activity

I take part in mathematics competitions

I do mathematics more than 2 hours a day outside of school

I play chess

I program computers

I participate in a mathematics club 


\section{Appendix Table B1. Distribution of responses to a selected question on each \\ PISA scale}

\begin{tabular}{|c|c|c|c|c|c|c|}
\hline \multirow[b]{2}{*}{ Example item } & \multirow[b]{2}{*}{ Response } & \multirow{2}{*}{$\begin{array}{c}\text { Natives } \\
\text { Australian }\end{array}$} & \multicolumn{4}{|c|}{$\begin{array}{c}\text { Second-generation immigrants - parental } \\
\text { origin }\end{array}$} \\
\hline & & & $\begin{array}{c}\text { High- } \\
\text { performing } \\
\text { East Asian }\end{array}$ & $\begin{array}{l}\text { Low- } \\
\text { performing } \\
\text { East Asian }\end{array}$ & $\begin{array}{l}\text { Indian } \\
\text { region }\end{array}$ & UK \\
\hline \multirow{4}{*}{$\begin{array}{l}\text { Work ethic. "I study until I } \\
\text { understand everything" }\end{array}$} & Strongly agree & 13 & 34 & 13 & 27 & 15 \\
\hline & Agree & 43 & 44 & 53 & 53 & 42 \\
\hline & Disagree & 38 & 19 & 29 & 18 & 37 \\
\hline & Strongly disagree & 6 & 2 & 5 & 1 & 7 \\
\hline \multirow{4}{*}{$\begin{array}{l}\text { Perceived control. "If I put in } \\
\text { enough effort I can succeed in } \\
\text { mathematics" }\end{array}$} & Strongly agree & 52 & 63 & 63 & 65 & 51 \\
\hline & Agree & 46 & 36 & 34 & 32 & 45 \\
\hline & Disagree & 3 & 1 & 3 & 3 & 2 \\
\hline & Strongly disagree & 0 & 0 & 1 & 0 & 1 \\
\hline \multirow{4}{*}{$\begin{array}{l}\text { Attributions to failure. "This week I } \\
\text { made bad guesses on the quiz" }\end{array}$} & Very likely & 7 & 4 & 8 & 12 & 8 \\
\hline & Likely & 32 & 24 & 28 & 24 & 29 \\
\hline & Unlikely & 36 & 33 & 36 & 31 & 37 \\
\hline & Very unlikely & 26 & 39 & 28 & 34 & 26 \\
\hline \multirow{5}{*}{$\begin{array}{l}\text { Perseverance. "When confronted } \\
\text { with a problem, I give up easily" }\end{array}$} & Very much like me & 4 & 4 & 3 & 2 & 3 \\
\hline & Mostly like me & 9 & 4 & 5 & 2 & 8 \\
\hline & Somewhat like me & 26 & 27 & 39 & 24 & 24 \\
\hline & Not much like me & 43 & 49 & 36 & 50 & 43 \\
\hline & Not at all like me & 18 & 16 & 18 & 22 & 22 \\
\hline \multirow{4}{*}{$\begin{array}{c}\text { Teacher support. "The teacher } \\
\text { shows an interest in every student's } \\
\text { learning" }\end{array}$} & Strongly agree & 39 & 40 & 41 & 42 & 39 \\
\hline & Agree & 34 & 34 & 36 & 30 & 32 \\
\hline & Disagree & 20 & 18 & 22 & 25 & 23 \\
\hline & Strongly disagree & 7 & 8 & 2 & 3 & 7 \\
\hline \multirow{4}{*}{$\begin{array}{l}\text { Subjective norms. "My parents } \\
\text { believe it's important for me to study } \\
\text { mathematics" }\end{array}$} & Strongly agree & 44 & 64 & 56 & 77 & 46 \\
\hline & Agree & 50 & 34 & 39 & 16 & 47 \\
\hline & Disagree & 5 & 2 & 4 & 7 & 6 \\
\hline & Strongly disagree & 1 & 0 & 0 & 0 & 1 \\
\hline \multirow{4}{*}{$\begin{array}{c}\text { Instrumental motivation. "Learning } \\
\text { mathematics is worthwhile for me } \\
\text { because it will improve my career } \\
\text { prospects" }\end{array}$} & Strongly agree & 33 & 40 & 40 & 45 & 39 \\
\hline & Agree & 54 & 50 & 50 & 41 & 46 \\
\hline & Disagree & 10 & 7 & 8 & 15 & 10 \\
\hline & Strongly disagree & 4 & 3 & 2 & 0 & 5 \\
\hline \multirow{4}{*}{$\begin{array}{l}\text { Attitude towards school. "Trying } \\
\text { hard at school will help me get a } \\
\text { good job" }\end{array}$} & Strongly agree & 49 & 45 & 53 & 57 & 52 \\
\hline & Agree & 46 & 49 & 42 & 40 & 42 \\
\hline & Disagree & 4 & 5 & 4 & 2 & 6 \\
\hline & Strongly disagree & 1 & 1 & 1 & 1 & 0 \\
\hline \multirow{4}{*}{$\begin{array}{l}\text { Maths behaviour. "I take part in } \\
\text { mathematics competitions" }\end{array}$} & Always/almost always & 2 & 16 & 5 & 11 & 2 \\
\hline & Often & 5 & 15 & 9 & 14 & 4 \\
\hline & Sometimes & 16 & 30 & 19 & 26 & 14 \\
\hline & Never / rarely & 77 & 39 & 66 & 50 & 80 \\
\hline Unweighted n & & 8,454 & 281 & 296 & 103 & 1,104 \\
\hline
\end{tabular}




\section{Appendix C. Differences in quality of school attended by Australian natives and second- generation East Asian immigrants}

The main body of the paper illustrated how the inclusion of a school level fixed effect led to a substantial decline in the second-generation East Asian parameter estimate. One interpretation is that this result has been driven by East Asian families choosing to send their offspring to higher quality schools. This appendix examines this proposition in more detail.

To do so, various pieces of school-level information are drawn upon, much of which has been collected as part of the PISA school questionnaire. Specifically, as part of the PISA 2012 study, principals were asked a series of questions about their school. This included both factual information (e.g. whether it is a private school, the proportion of maths teachers who hold a maths degree) and their subjective views. The latter involved answering a series of related questions which have been converted into scales by the survey organisers, including indicators of school climate, teacher morale, availability of extra-curricular activities and the quality of the school's educational resources. In the following analysis, these scales are standardised to have a mean of 0 and a standard deviation of 1 across the Australian population. Moreover, the direction of certain scales have been changed to ensure that larger positive values always refer to more positive responses (e.g. a value of 1 on the teacher shortages scale means that there is less likely to be teacher shortages in the school compared to a value of, say, 0). Appendix Table $\mathrm{C} 1$ provides further information on the questions asked as part of each scale.

Two indicators of school-peer quality have also been derived. The first is calculated as the average maths test score of all other sampled children who attend the same school. The second is the average socio-economic status (SES) of all other sampled children in the same school, with SES defined using the ISEI index of occupational prestige (the highest value out of the child's mother or father). For ease of interpretation, these peer quality scales have also been standardised to have a mean of 0 and standard deviation of 1 within the Australian population.

Descriptive statistics for each of these 'school quality' indicators can be found in Appendix Table C2. These refer to either percentages (variables above the dashed line) or mean values on the standardised scales. Positive figures always refer to attendance at a "higher quality" school. 
Each of the variables presented in Appendix Table C2 is used as a dependent variable in an OLS regression model of the form:

$Q_{i j}=\alpha+\beta . I_{i}+\delta . D_{i}+\varepsilon_{i j}$

Where:

$\mathrm{Q}=$ One of the indicators of school quality (as given in Appendix Table C2)

$\mathrm{I}=\mathrm{A}$ vector of second-generation immigrant dummy variables (reference $=$ Australiannatives)

$\mathrm{D}=\mathrm{A}$ vector of demographic characteristics (e.g. age, gender, state, parental education)

$\varepsilon=$ Individual random error term

$\mathrm{i}=$ Pupil i

$\mathrm{j}=$ School $\mathrm{j}$

Model C1 is estimated 11 times, once using each of the school quality variables (Q). Vector D includes controls for mothers' education, fathers' education, mothers' occupation, fathers' occupation, mothers' current work status, fathers' current work status, household wealth, language most often spoken at home, Australian state, urban or remote location, family structure, age and gender. The parameter of interest is $\beta$ for the second-generation East Asian immigrant group. This reveals whether there is a difference in school quality) between Australian natives and second-generation East Asian immigrants, after accounting for differences in demographic characteristics.

Results can be found in Appendix Table C2 and Appendix Figure C1. The former illustrates that, although children of East Asian descent are no more likely to attend a private school than a child with two Australian-born parents, they are 12 percentage points more likely to attend an academically selective $\operatorname{school}^{24}$. Moreover, approximately 10 percent more maths teachers hold a maths degree (on average) in the schools that second-generation East

\footnotetext{
${ }^{24}$ Principals were asked "How often the following factors are considered when students are admitted to your school?" (a) students' record of academic performance (including placement tests); (b) recommendation of feeder schools, along with three possible response options (never, sometimes, always). Schools are defined as "academically selective" if principals responded "always" to at least one of these two questions.
} 
Asian immigrants attend. Differences with respect to Australian natives are statistically significant at the five percent level.

This is further supported by Appendix Figure C3. This plots the difference between Australian natives and second-generation East Asian immigrants for each of the "school quality" standardised scale scores (both those based upon principals' subjective responses and the derived measures of peer quality). There are particularly large differences in schoolpeers maths test scores; the peers of East Asian children score, on average, 0.65 standard deviations higher on the PISA maths test than those of native Australian children. This suggests that East Asian families are much more likely to send their offspring to schools with higher overall levels of academic achievement. Similarly, children of East Asian heritage attend schools that have (on average) 0.4 standard deviations better "school climate ${ }^{25}$ ", 0.2 standard deviations better educational resources ${ }^{26}$ and are 0.2 standard deviations less likely to have teacher shortages ${ }^{27}$ (compared to their Australian heritage peers). These differences are all statistically significant at (at least) the 10 percent level. Moreover, Appendix Figure $\mathrm{C} 1$ also suggests that second-generation East Asian immigrants have more socioeconomically advantaged school peers than the native-Australian group (even after their own family background has been taken into account).

Overall, this appendix therefore supports the proposition that East Asian families tend to send their children to "higher quality" schools than Australian families, even when they share similar socio-economic backgrounds. This is likely to reflect the high value East Asian families place upon their children's education. It is also consistent with my suggestion that the school level fixed effect included in model 3 (Table 2) partly captures this important element of East Asian culture.

\footnotetext{
${ }^{25}$ An example of a question on this scale is "In your school, to what extent is the learning of students hindered by student truancy?"

${ }^{26}$ An example of a question on this scale is "Is your school's capacity to provide instruction hindered by a shortage of instructional materials?"

${ }^{27}$ An example of a question on this scale is "Is your school's capacity to provide instruction hindered by a lack of qualified maths teachers?"
} 


\section{Table C1. The PISA principal questionnaire scales and example items}

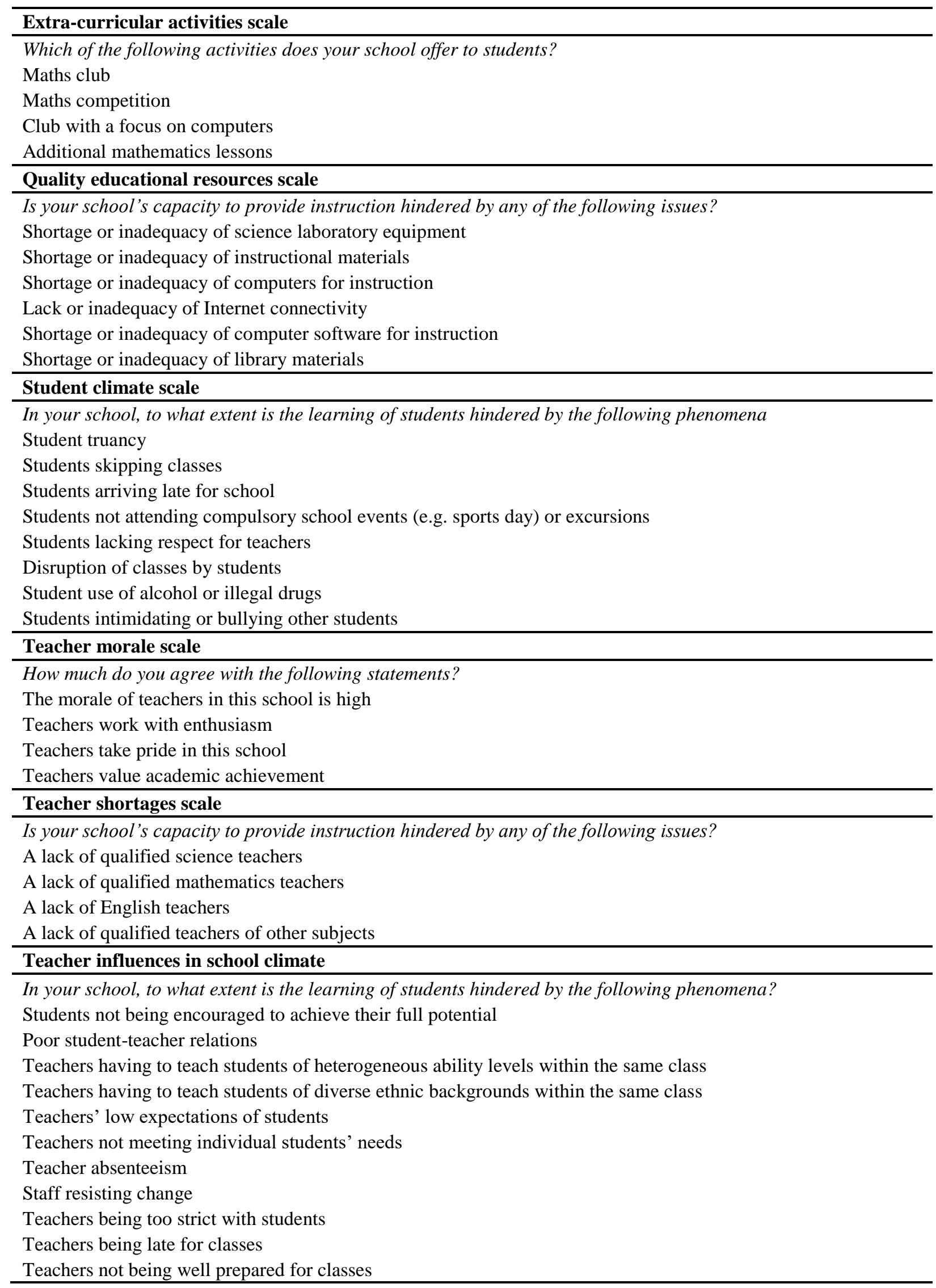


Table C2. Differences in various aspects of school quality between Australian natives and second-generation immigrant groups

\begin{tabular}{|c|c|c|c|c|c|}
\hline & \multirow{2}{*}{$\begin{array}{c}\text { Natives } \\
\text { Australian }\end{array}$} & \multicolumn{4}{|c|}{ Second-generation immigrants - parental origin } \\
\hline & & $\begin{array}{c}\text { High- } \\
\text { performing East } \\
\text { Asian } \\
\end{array}$ & $\begin{array}{c}\text { Low- } \\
\text { performing } \\
\text { East Asian } \\
\end{array}$ & $\begin{array}{l}\text { Indian } \\
\text { region }\end{array}$ & $\begin{array}{c}\text { United } \\
\text { Kingdom }\end{array}$ \\
\hline Private school \% & 12 & 16 & 11 & 7 & 15 \\
\hline$\%$ maths teachers with maths degree & 60 & 80 & 70 & 69 & 62 \\
\hline$\%$ in academically selective schools & 43 & 58 & 45 & 60 & 43 \\
\hline Average math score of school peers & -0.10 & 0.76 & 0.13 & 0.26 & -0.01 \\
\hline Average SES of school peers & -0.03 & 0.23 & -0.01 & 0.07 & 0.03 \\
\hline Extra-curricular activities scale & -0.02 & 0.18 & 0.11 & 0.22 & 0.02 \\
\hline Quality educational resources scale & -0.04 & 0.32 & 0.09 & 0.23 & 0.09 \\
\hline Student climate scale & -0.04 & 0.41 & 0.18 & 0.22 & 0.09 \\
\hline Teacher morale scale & -0.03 & 0.24 & 0.03 & 0.09 & 0.08 \\
\hline Teacher shortages scale & -0.06 & 0.51 & 0.28 & 0.32 & 0.12 \\
\hline Teacher influences in school climate & -0.02 & 0.15 & -0.06 & 0.04 & 0.08 \\
\hline Unweighted $n$ & 8,454 & 281 & 296 & 103 & 1,104 \\
\hline
\end{tabular}


Appendix Table C3. Differences in school quality indicators between Australian natives and second-generation East Asian immigrants (controlling for differences in demographic characteristics)

\begin{tabular}{lcc}
\hline & $\begin{array}{c}\text { Percentage } \\
\text { point difference }\end{array}$ & $\begin{array}{c}\text { Standard } \\
\text { error }\end{array}$ \\
\hline Private school & -0.2 & 3.8 \\
Maths teachers with maths degree & 10.0 & 2.8 \\
Academic selectivity & 11.6 & 4.9 \\
\hline
\end{tabular}

Notes: Author's calculations using the Australian PISA 2012 dataset. Estimates from a linear probability model, controlling for mother education, father education, mother occupation, father occupation, mother current work status, father current work status, household wealth scale, language most often spoken at home, Australian state, urban or remote location, family structure, age and gender. Figures refer to percentage point differences between Australian natives and second-generation East Asian immigrants. 


\section{Appendix Figure C1. Differences in school quality indicators between Australian natives and second-generation East Asian immigrants (controlling for differences in demographic characteristics)}

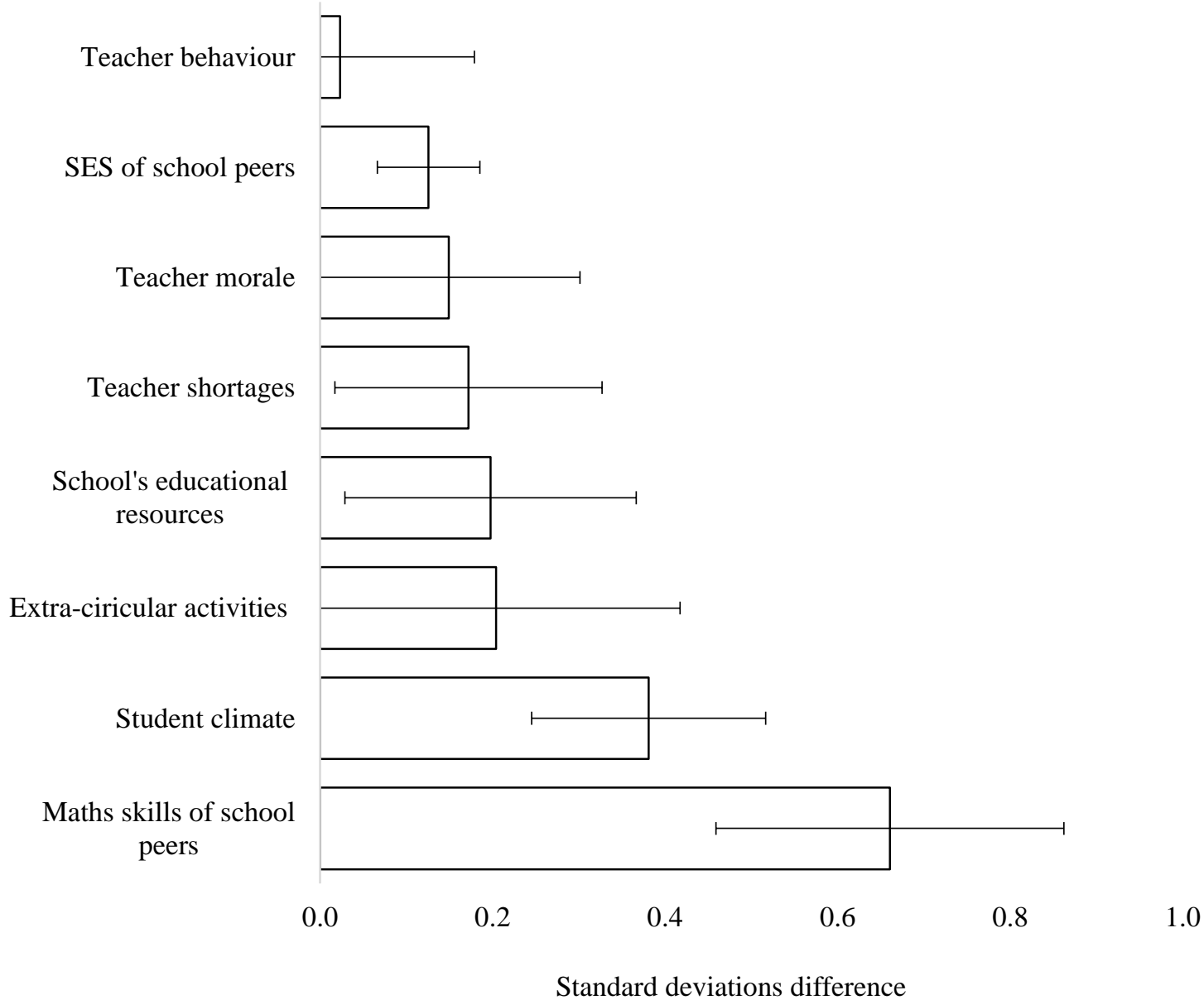

Notes: Author's calculations using the PISA 2012 Australian dataset. Figures refer to differences between Australian natives and second-generation East Asian immigrants in terms of national standard deviations. All scales have been recoded so that positive values refer to more positive responses. Model includes controls for mother education, father education, mother occupation, father occupation, mother current work status, father current work status, household wealth scale, language most often spoken at home, Australian state, urban or remote location, family structure, age and gender. Thin black line running through the centre of the bars illustrate the estimated 90 percent confidence interval. 


\section{Appendix D. Alternative estimates - excluding the school-level fixed effect}

Appendix Table D1 presents alternative estimates where the school fixed effect has been removed from the model. All figures refer to differences in standardised PISA maths test scores between Australian natives and second-generation East Asian immigrants from highperforming countries. The purpose is to investigate if the broad pattern of results stays the same - particularly how the parameter estimates change between the different model specifications. In the main body of the paper, the school fixed effect was entered in model 3 onwards. Hence the figures of interest in Appendix Table D1 come from models 4 to 10.

The broad pattern of results is similar whether the school fixed effect is included in the model or not. There is no decline in the parameter estimate between models 3 and 4 (when controlling for effort on the PISA test). However, a substantial decline is observed in both model 5 (controlling for time spent studying outside of school) and model 6 (controlling for the work ethic, perseverance, perceived control and attributions to failure scales). Estimates are then stable until models 9 and 10, when another slight decline can be observed once maths behaviour and educational expectations are included in the model. The magnitude of the decline is always slightly greater in the models excluding the school fixed effect - but often by quite small amounts. For instance, the parameter estimate declines by 0.05 standard deviations between models 5 and 6 when the fixed effect is included, and 0.06 when it is not. The more notable difference between the two sets of estimates presented in Appendix Table D1 is that, even after controlling for a host of factors in Model 10, differences between Australian natives and second-generation East Asian immigrants after much smaller when the fixed effect is included ( 0.15 standard deviations) compared to when it has been excluded (0.48 standard deviations). This provides further evidence that school level factors play a key role in explaining differences in maths test scores between these groups (over and above what can be explained by differences in their attitudes, expectations and beliefs). 


\section{Appendix Table D1. A comparison of estimates with and without including the school-level fixed effect}

\begin{tabular}{lcccc}
\hline & \multicolumn{2}{c}{ With Fixed Effect } & \multicolumn{2}{c}{ Without Fixed Effect } \\
& Beta & SE & Beta & SE \\
\hline Model 1 & 1.02 & 0.10 & 1.02 & 0.10 \\
Model 2 & 0.84 & 0.10 & 0.84 & 0.10 \\
Model 3 & 0.41 & 0.07 & - & - \\
\hline Model 4 & 0.41 & 0.07 & 0.84 & 0.10 \\
Model 5 & 0.29 & 0.07 & 0.67 & 0.09 \\
Model 6 & 0.24 & 0.07 & 0.61 & 0.09 \\
Model 7 & 0.25 & 0.07 & 0.62 & 0.09 \\
Model 8 & 0.26 & 0.07 & 0.63 & 0.09 \\
Model 9 & 0.20 & 0.06 & 0.56 & 0.09 \\
Model 10 & 0.15 & 0.06 & 0.48 & 0.08 \\
\hline n & \multicolumn{3}{c}{$\mathbf{8 , 5 3 9}$} & $\mathbf{8 , 5 3 9}$ \\
\hline
\end{tabular}

Notes: Figures refer to differences in PISA maths test scores between Australian natives and second-generation East Asian immigrants from a high-performing countries. All figures reported in terms of international standard deviations (multiplying figures by 100 gives differences in terms of PISA points). Model refers to the regression model specification used (this is to be cross-referenced with Tables 2, 3 and 4). Left hand columns include a schoollevel fixed effect in model 3 onwards, figures in the right hand column do not. 